\title{
Inflammatory process in Alzheimer's Disease
}

\section{Marco A. Meraz-Ríos ${ }^{1 \dagger}$, Danira Toral-Rios ${ }^{2}$, Diana Franco-Bocanegra ${ }^{3}$, Juana Villeda-Hernández ${ }^{4}$ and Victoria Campos-Peña ${ }^{5 *}$}

1 Departamento de Biomedicina Molecular, Centro de Investigación y de Estudios Avanzados, Mexico City, Mexico

2 Departamento de Fisiología Biofísica y Neurociencias, Centro de Investigación y de Estudios Avanzados, Mexico City, Mexico

${ }^{3}$ Posgrado en Ciencias Biológicas, Universidad Nacional Autónoma de México, Mexico City, Mexico

${ }^{4}$ Departamento de Neuropatología Experimental, Instituto Nacional de Neurología y Neurocirugía, Mexico City, Mexico

${ }^{5}$ Laboratorio Experimental de Enfermedades Neurodegenerativas, Instituto Nacional de Neurología y Neurocirugía Manuel Velasco Suárez, Mexico City, Mexico

\section{Edited by:}

Beatriz Gomez-Gonzalez,

Universidad Autonoma

Metropolitana, Unidad Iztapalapa,

Mexico

\section{Reviewed by:}

Benjamín Florán, Centro de Investigación y de Estudios

Avanzados del IPN, Mexico

Clorinda Arias, Universidad Nacional

Autónoma de México, Mexico

Abbas Mirshafiey, Tehran University

of Medical Sciences, Iran

*Correspondence:

Victoria Campos-Peña, Laboratorio Experimental de Enfermedades

Neurodegenerativas, Instituto

Nacional de Neurología y

Neurocirugía Manuel Velasco

Suárez, Insurgentes Sur 3877, ZIP

14269, Mexico City, Mexico

e-mail: neurovcp@ymail.com

${ }^{\dagger}$ Present address:

Marco A. Meraz-Ríos,

Departamento de Biomedicina

Molecular, Centro de Investigación y

de Estudios Avanzados, Av. Instituto

Politécnico Nacional 2508, ZIP

07360, Mexico City, Mexico
Alzheimer Disease (AD) is a neurodegenerative disorder and the most common form of dementia. Histopathologically is characterized by the presence of two major hallmarks, the intracellular neurofibrillary tangles (NFTs) and extracellular neuritic plaques (NPs) surrounded by activated astrocytes and microglia. NFTs consist of paired helical filaments of truncated tau protein that is abnormally hyperphosphorylated. The main component in the NP is the amyloid- $\beta$ peptide $(A \beta)$, a small fragment of $40-42$ amino acids with a molecular weight of $4 \mathrm{kD}$. It has been proposed that the amyloid aggregates and microglia activation are able to favor the neurodegenerative process observed in $A D$ patients. However, the role of inflammation in $A D$ is controversial, because in early stages the inflammation could have a beneficial role in the pathology, since it has been thought that the microglia and astrocytes activated could be involved in $A \beta$ clearance. Nevertheless the chronic activation of the microglia has been related with an increase of $A \beta$ and possibly with tau phosphorylation. Studies in AD brains have shown an upregulation of complement molecules, pro-inflammatory cytokines, acute phase reactants and other inflammatory mediators that could contribute with the neurodegenerative process. Clinical trials and animal models with non-steroidal anti-inflammatory drugs (NSAIDs) indicate that these drugs may decrease the risk of developing $A D$ and apparently reduce $A \beta$ deposition. Finally, further studies are needed to determine whether treatment with anti-inflammatory strategies, may decrease the neurodegenerative process that affects these patients.

Keywords: Alzheimer disease, amyloid- $\beta$, neurodegeneration, microglia, astrocyte, neuroinflammation, pro-inflammatory cytokine, anti-inflammatory strategies

\section{INTRODUCTION}

Alzheimer's disease (AD) is the most common cause of dementia in elderly adults. $\mathrm{AD}$ is clinically characterized by progressive loss of memory and other cognitive functions. Histopathologically is recognized by the presence of neuritic plaques (NPs) and neurofibrillary tangles (NFTs). The origin causes of $\mathrm{AD}$ can be classified as familial or sporadic. The incidence of familial cases is low $(5-10 \%)$ and is related to the presence of mutations in three different genes: presenilin-1 (PS1), presenilin2 (PS2), and amyloid- $\beta$ precursor protein (APP- $\beta$ ) (ChartierHarlin et al., 1991; Goate et al., 1991; Murrell et al., 1991; Levy-Lahad et al., 1995; Duff et al., 1996; Sisodia et al., 1999). Sporadic AD represents $90-95 \%$ of total cases, and although its etiology is multi-factorial, age is the main risk factor. Although there are different genetic and environmental causes, all patients have a similar clinical behavior and develop identical brain lesions: NFTs consisting of Tau $(\tau)$ protein and NPs consisting of amyloid- $\beta(A \beta)$ peptides. These alterations are the final result of post-translational modifications and involve different genes and render $\mathrm{AD}$ as a complex multigenic neurodegenerative disorder.
In addition to this multi-genic complexity in $\mathrm{AD}$, now we know that $A \beta$ promotes an inflammatory response mediated by microglia and astrocytes, thus activating signaling pathways that could lead to neurodegeneration. It is currently unknown whether brain inflammation in $\mathrm{AD}$ patients is the cause of the disease or a secondary phenomenon. Although it was previously thought that the central nervous system (CNS) was an immune-privileged site, now is well known that certain features of inflammatory processes occur normally in response to an injury, infection or disease. The resident CNS cells generate inflammatory mediators, such as pro-inflammatory cytokines, prostaglandins (PGs), free radicals, complement factors, and simultaneously induce the production of adhesion molecules and chemokines, which could recruit peripheral immune cells. This review describes the cellular and molecular mediators involved in the inflammatory process associated with $\mathrm{AD}$ and several possible therapeutic approaches describe recently.

\section{NPs AND A $\beta$ IN THE NEURO-INFLAMMATORY PROCESS}

NPs, are extracellular deposits structures that contain a highly insoluble fibrillar $A \beta$ core formed by fragments of 39-42 amino 
acids surrounded by microglia, reactive astrocytes, and dystrophic neurites produced from degenerating neuronal processes (Iversen et al., 1995). A $\beta$ normally originates from APP- $\beta$ (Kang et al., 1987) through the sequential action of beta secretase and the multi-protein gamma-secretase complex.

$\mathrm{A} \beta$ accumulation in the brain, in one of the main pathological processes of $\mathrm{AD}$ patients. The formation of these deposits initiates a series of cellular events which are able to elicit an immune response where resident cells such as microglia and astrocytes could participate. $\mathrm{A} \beta$ accumulation in parenchyma and blood vessels causes microglial migration and promotes acute and chronic inflammatory responses against the aggregates, thus inducing the production of nitric oxide (NO), reactive oxygen species (ROS), pro-inflammatory cytokines (TNF $\alpha$, IL- $1 \beta$ and IL6 ), and PGs (PGE2), which eventually could promote neuronal death (Figure 1) (Akiyama et al., 2000; Kitazawa et al., 2004).

\section{CELLULAR MEDIATORS \\ MICROGLIA}

Microglia are resident brain cells, derived from monocyte precursors cells during embryogenesis, and are able to provide the initial response against any injury that occurs in the CNS. Although these cell were observed by Nissl over 100 years ago, their definitive identification and characterization was performed by Mrak (2012). Activated microglial association around NPs suggested that microglia participate in the accumulation of the $A \beta$ observed in $\mathrm{AD}$ patients (Glenner et al., 1984); this hypothesis was supported by several studies (Rozemuller et al., 1986; Dickson et al., 1988).

Normally, microglia exists in an inactive state; morphologically, these cells have a small soma with branching processes. When activated by pathogens or injury, these cells suffer visible morphological changes, including decreased branching and soma growth, the acquisition of an amoeboid form and display a wide variety of specific cellular surface markers (Town et al., 2005). NPs in $\mathrm{AD}$ patients' brain activate the inflammatory response mediated by microglia and cause pro-inflammatory cytokine secretion, which may directly cause neuronal injury.

Microglia in vitro cell cultures are able to phagocyte the amyloid peptide. However, ultrastructural analysis of tissues from $\mathrm{AD}$ patients demonstrated that there is no presence of amyloid fibrils in the lysosomal compartments of local microglia cells (Frackowiak et al., 1992). Whereas microglia has the ability to phagocyte $\mathrm{A} \beta$ in vitro, its phagocytosis capacity is limited. An important observed feature was the abnormal presence of macrophages infiltrating from the periphery, which showed amyloid fibers in their lysosomal compartments (Wisniewski et al., 1991; Akiyama et al., 1996). Currently, we know that there are two types of phagocytic cells within the CNS that are able to initiate the innate immune response: microglia and peripheral macrophages (Rezai-Zadeh et al., 2009; Gate et al., 2010). These macrophages are recruited into the CNS by specific cytokines and

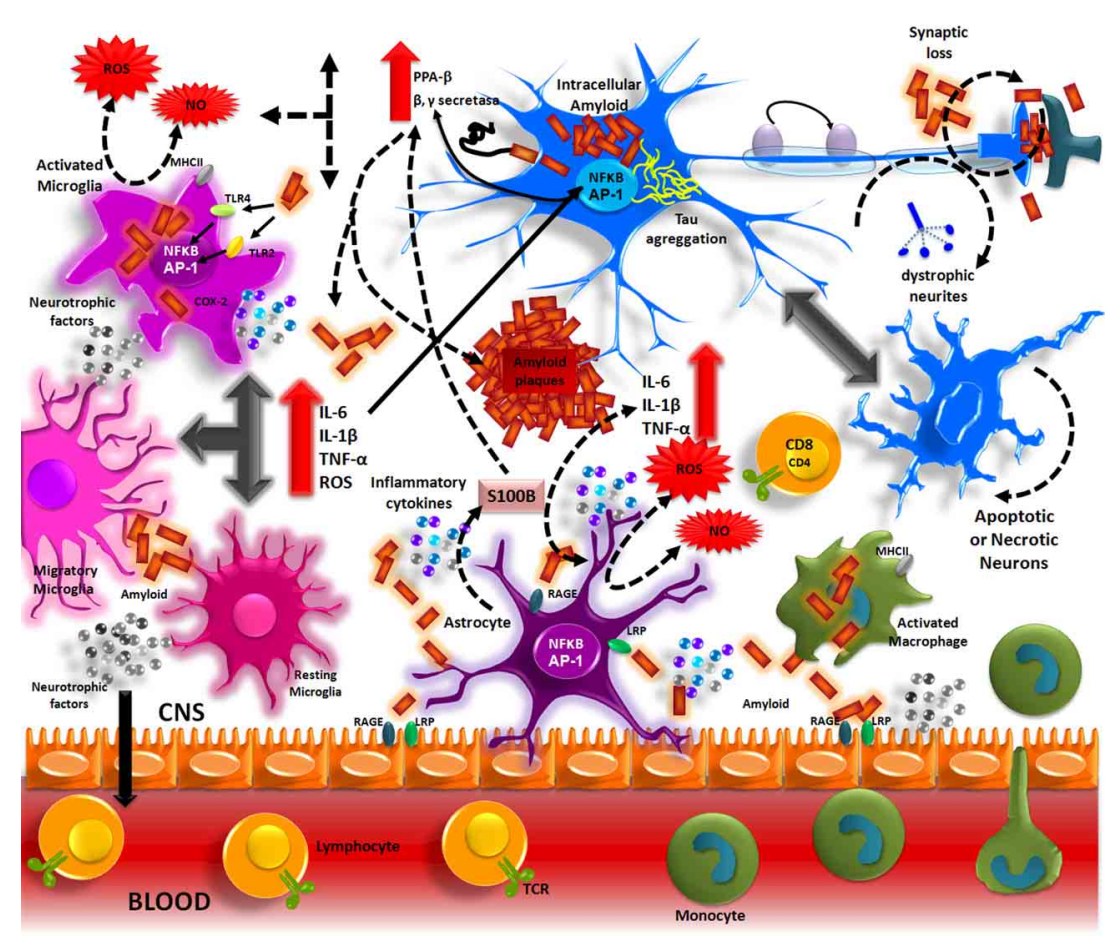

FIGURE 1 | Inflammation in Alzheimer's disease. The A $\beta$ peptide produced by APP processing, form aggregates that activate microglia through TLRs and RAGE receptors. These receptors in turn, activate NF-kB and AP-1 transcription factors, which induce the reactive oxygen species (ROS) production and the expression of inflammatory cytokines (IL-1, IL-6, TNF).
These inflammatory factors directly acting on the neurons and also stimulate the astrocytes, which amplify the pro-inflammatory signals, inducing a neurotoxic effects. The inflammatory mediators generate by resident CNS cells, induce the production of adhesion molecules and chemokines, which recruit peripheral immune cells. 
chemokines, which are released during microglial and astrocytic activation and are able to cross the blood-brain barrier.

Similarly to macrophages, microglia recognizes pathogens through pattern recognition receptors (PRRs), which include specific toll-like receptors (TLRs), nucleotide-oligomerization binding domain (NOD) proteins, and C-type lectin receptors. These receptors interact with pathogen-associated molecular patterns (PAMPs) or damage-associated molecular patterns (DAMPs) to initiate the cellular defense mechanisms (Sterka and Marriott, 2006; Rubartelli and Lotze, 2007). Thus, the formation and release of ROS, pro-inflammatory cytokines (IL-1 $\beta$, IL-6, TNF- $\alpha$, and IFN- $\gamma$ ) (Lue et al., 2001), chemokines (MIP1 $\alpha$, MIP1 $\beta$, RANTES, and MCP1), and growth factors such as macrophage colony-stimulating factor (MCSF) and complement factors (C1q, C3, C4, and C9) (Walker et al., 1995) begin. In addition to the before mentioned molecules, microglia is also able to express receptors for advanced glycosilation end products (RAGE), Fc receptors, CD40, FP receptors, and various scavengertype receptors (El Khoury et al., 1998; Tan et al., 1999; Walker and Lue, 2005; Okun et al., 2010). Although microglia has the capacity to respond to various stimuli, the presence of $A \beta$ is particularly important. $A \beta$ induces a high accumulation of surface molecules of type I and II major histocompatibility complex (MHC) (McGeer et al., 1988).

Microglial cells primarily have an immunomodulatory role and express a large variety of immune response-related antigens and molecules; however, the specific role of microglia within the CNS remains controversial. Microglial activation is not a simple and unique phenomenon; instead, activation is a continuous series of events in which microglia awakens innate and adaptive phagocytic immune responses and consistently display activation through antigens on the cellular surface (Town et al., 2005). Under this principle, microglia displays a "variable" response, in which a mixture of the classical activation pathway and exacerbated increase of alternative activation can be observed in AD patients, which could leads to irreparable damage that result in persistent neurodegeneration.

\section{ASTROCYTES}

Astrocytes are the most abundant glial cells present in the CNS and have important functions in brain organization and maintenance (Sofroniew and Vinters, 2010). These cells interact with neurons and are involved in neurotransmitter secretion and recycling, ion homeostasis, energy metabolism regulation, synaptic remodeling and modulation of oxidative stress, information processing, and signal transmission (Halassa and Haydon, 2010; Henneberger et al., 2010).

In early stages of $\mathrm{AD}$, activated astrocytes are located in two regions: the molecular layer of the cerebral cortex and near the amyloid deposits below the pyramidal cell layer. The mechanisms leading to the activation of these cells in response to the pathological changes produced by $\mathrm{AD}$ are not obvious, but it has been demonstrated that the presence of amyloid activates astrocytes. Activated astrocytes can phagocytose and degrade amyloid, which suggests that they importantly contribute to the removal of accumulated $A \beta$ in parenchyma. Astrocytes and microglia are activated through TLRs and RAGE-dependent pathways, thus causing local inflammation that eventually could intensifies neuronal death.

Overall, the inflammatory process in $\mathrm{AD}$ patients is shown by changes in microglial morphology and astrogliosis, which is manifested by an increase in number, size and motility of astrocytes. Astrocyte activation is present in many neurodegenerative conditions, expressing high levels of glial fibrillary acidic protein (GFAP), vimentin, and nestin. Unfortunately, these changes cause a "disruption" of normal activities in astrocytes, which are essential for normal neuronal function. Maintenance of glutamate concentration in the extracellular space is among the normal physiological functions; altering homeostasis causes a local neuron depolarization, which leads to citotoxic damage. Thus, although astrocytic activation has a protective role in brain, intense activation exacerbates neuronal damage and accelerates disease progression.

Similarly to microglia, astrocytes quickly respond to injury; these cells are located near the fibrilar $A \beta$ deposits, which are responsible for the astroglial activation observed in $\mathrm{AD}$ patients. Injection of $A \beta$ oligomeric forms into the retrosplenial cortex of rats caused a significant astrocyte activation, as shown by transcription factor NF- $\mathrm{B}$ activation and the presence of inflammatory mediators such as tumor necrosis factor (TNF- $\alpha$ ), interleukin 1 (IL-1 $\beta$ ), and cyclooxygenase-2 (COX-2)(Carrero et al., 2012). The activated astrocytes express on their cell surface, receptors that bind the $A \beta$ peptides such as RAGE, receptor-like density lipoproteins, proteoglycans and various scavenger receptors (Wyss-Coray et al., 2003; Medeiros and Laferla, 2013). Thus, activated astrocytes are able to cause neurodegeneration and express inflammation-associated factors, such as $\mathrm{S} 100 \beta$, consequently inducing neurite outgrowth. $S 100 \beta$ expression correlates with the number of dystrophic neurites in AD patients (Mrak et al., 1996).

In astrocytes, NF- $\mathrm{B}$ significantly controls chemokine and adhesion molecules secretion, favors peripheral lymphocyte infiltration and increases inflammatory response (Moynagh, 2005); this process becomes a self-regulating mechanism, which leads to neurodegeneration.

\section{OLIGODENDROCYTES}

Although oligodendroglia is important to maintain neuron morphology and function, little is known about how they are affected by $A \beta$ deposits However, there are studies that indicate changes in white matter and abnormalities in myelin in $\mathrm{AD}$ patients (Kobayashi et al., 2002; Roth et al., 2005). Specifically, aberrations have been reported in the white matter of asymptomatic familial AD patients, particularly in patients with mutations in PS1 (Ringman et al., 2007). The presence of A $\beta$ in oligodendrocyte cultures caused cell death. Although cell death can be prevented by the presence of anti-inflammatory agents, morphological alterations of the cells persist, suggesting that the damage cannot be completely reversed (Roth et al., 2005). Subsequently, oligodendrocyte differentiation and function is affected by the simultaneous presence of mutations in PS1 (hPS1 ${ }^{M 146 V}$ ) and $\mathrm{A} \beta$ accumulation, as demonstrated in a mouse model. These abnormalities can lead to the development of abnormal patterns of myelin basic protein (MBP) (Desai et al., 2011), 
which completely alters oligodendrocyte homeostasis. Finally, the loss of trophic support provided by these cells might lead to increased neuronal vulnerability and inflammation, thus favoring neurodegeneration.

\section{MOLECULAR MEDIATORS OF INFLAMMATION IN AD}

The $A \beta$ deposition activates the acute immune response of microglial cells and astrocytes. At the same time, amyloid plaques are responsible for the production and the activation of inflammation-related proteins such as complement factors, acute-phase proteins, chemokines and cytokines like interleukin 1 (IL-1), interleukin 6 (IL-6), tumor necrosis factor $\alpha$ (TNF- $\alpha$ ), and transforming growth factor $\beta$ (TGF- $\beta$ ). These molecular mediators of inflammation have been linked with a series of concomitant deleterious and beneficial effects (Figure 2).

\section{THE COMPLEMENT SYSTEM}

The complement system is an important innate and adaptive immune response effector. This system is composed of a number of proteins and proteases that are activated in cascade (Forneris et al., 2012), and it appears to have a fundamental role in neurodegenerative diseases. Overall, the complement system uses the $\mathrm{C} 1 \mathrm{q}$ molecule, mannose-binding protein or the interaction with the C3 multifunctional protein to recognize certain molecular patterns on pathogens. C3 activation recruits cells with phagocytic activity, and Membrane Attack Complex (MAC) is formed by binding C5-C9 (Ricklin et al., 2010). In adaptive immune

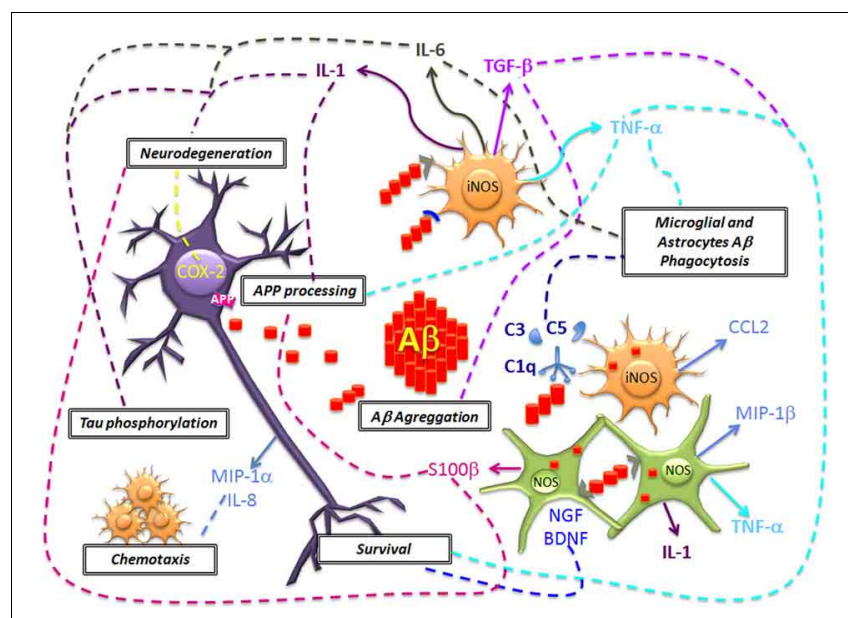

FIGURE 2 | Neuronal damage and A $\beta$ deposition triggers microglial and astrocytes activation and the generation of inflammation molecular mediators. The acute production of molecules of the complement system (C1q, C3, and C5), pro-inflammatory cytokines (IL-1, IL-6, TNF- $\alpha$ ), chemokines (CCL2, MIP-1 $\alpha$, MIP-1 $\beta$, and IL-8) mediate the A $\beta$ clearance. However, in a chronic stage these molecules could promote an increased expression and alteration of APP processing, A $\beta$ deposition, Tau phosphorylation and neurodegeneration. Also, another effect of glial cells includes the generation of NO that promotes oxidative stress. The inflammatory microenvironment favors the production of COX-2 in neurons that leads to apoptosis. In contrast, it has been proposed that glial cells could mediate neuronal survival, by the production of TGF- $\beta$ and neurotrophic factors (BDNF and NGF), but the disease progression results in failure to repair neurons. response, the complement system is involved in T-cell response regulation and T-helper lymphocyte differentiation (Pekkarinen et al., 2011).

In neurodegenerative diseases, there is a deregulation of the classical complement pathway. Studies in $\mathrm{AD}$ patient brains have revealed an increase in the immunoreactivity of $\mathrm{Clq}, \mathrm{C} 3 \mathrm{~b}, \mathrm{C} 4 \mathrm{~d}$, C5b-9, and MAC surrounding senile plaques (McGeer et al., 1989; Rogers et al., 1992) and microglia surrounding the fibrillar aggregates of $A \beta$ in the microvasculature (Fan et al., 2007). The co-existence of these molecules with the $A \beta$ aggregates suggests a possible link between classical complement pathway activation, inflammation and pathological aggregation of $A \beta$. A decrease in $\mathrm{C} 1 \mathrm{q}$ levels has been reported in cerebrospinal fluid (CSF) of AD patient and this result contrasts with an increase of $\mathrm{Clq} \mathrm{lev-}$ els in the CNS (Smyth et al., 1994). In vitro studies revealed that $\mathrm{C1q}$ recognizes fibrillar and aggregated forms of $\mathrm{A} \beta 1-42$ and $A \beta 1-40$, but not the monomeric forms. The C1q receptor is expressed in microglia, which contributed to the belief that the increase of this molecule in $\mathrm{AD}$ patient brains could affect the phagocytosis of $A \beta$. However, in primary microglia rat culture studies, exposure to $A \beta 1-42$ and a nanomolar concentration of C1q caused a decrease in the phagocytosis of $A \beta$, compared to cultures exposed only to A $\beta 1-42$ (Webster et al., 2000). A similar result was observed in a transgenic mouse model, which expressed mutated hAPP and an absence of Clq expression (APPQ ${ }^{-/-}$). These mice showed no change in the amount of $A \beta$ aggregates, but a decrease in glial cells activation was observed (Fonseca et al., 2004), thus establishing that C1q importantly contributes to microglial activation.

Microglia cells also produce C3. When these cells are exposed to $A \beta$ synthetic peptides, their activation can be observed as well as an increase in C3 synthesis to 5-to 10 fold (Haga et al., 1993). When this molecule is inhibited, in the brain of an hAPP transgenic model, by the overexpression of the soluble form of the protein related to the complement receptor (sCrry), a 2- to 3-fold increase in $A \beta$ deposits formation was observed in one-year-old hAPP/sCrry mice, which was accompanied by extensive neurodegeneration (Wyss-Coray et al., 2002). APP/C3 ${ }^{-/-}$double transgenic generation confirmed that the molecule modulated the microglia phenotype, and promotes $\mathrm{A} \beta$ degradation (Maier et al., 2008).

Complement receptor 1 (CR1) is expressed in cells with phagocytic activity, $\mathrm{C} 3 \mathrm{~b}$ and $\mathrm{C} 4 \mathrm{~b}$ are CR1 ligands, and their binding facilitates phagocytosis. Genome-wide association studies (GWAS) in AD patients have shown a direct relationship between CR1 gene variants with cognitive impairment in patients and an increase in amyloid plaque formation (Chibnik et al., 2011).

The anaphylatoxin (C5) has been linked to excitotoxicity and apoptosis activation in the CNS, which is believed to play an important role in the development of neurodegenerative diseases. This molecule also promotes chemotaxis and glial cells activation. In $\mathrm{AD}$ animal models, the use of the $\mathrm{C} 5 \mathrm{a}$ receptor antagonist $(\mathrm{C} 5 \mathrm{aR}$ or $\mathrm{CD} 88)$ reduces the amount of $\mathrm{A} \beta$ aggregates and hyperphosphorylated tau protein (Fonseca et al., 2009; Ager et al., 2010). It appears that the complement system activation in AD 
might have beneficial effects for $\mathrm{A} \beta$ clearance; however, this activation could eventually become deregulated and favor neurotoxic effects by promoting unwanted inflammation. For these reasons, more studies are required to understand the changes affecting the complement system in $\mathrm{AD}$ development.

\section{CYTOKINES}

Immune system cells are able to produce cytokines, which are soluble proteins that mediate inflammation. In the CNS, cytokines are produced by microglial cells and astrocytes and play a key role in CNS development during the embryonic stages. Cytokines are involved in the inflammatory processes of neurodegenerative diseases. In $\mathrm{AD}$, these proteins may be important in the development of the pathology. Studies of AD patient tissues and CSF have shown elevated levels of pro-inflammatory cytokines such as IL-1 $\beta$, IL-6, IL-10, TNF- $\alpha$, and TGF- $\beta$ (Blum-Degen et al., 1995; Tarkowski et al., 2002; Mrak and Griffin, 2005; Jiang et al., 2011). The increase of these cytokines is strongly related to microglia activation by exposure to A $\beta$ aggregates (Meda et al., 1999). Animal models that overexpress the mutant hAPP protein have shown a direct relationship between the amount of $A \beta$ aggregates and elevated levels of TNF- $\alpha$, IL-6, IL-12, IL- $1 \beta$, and IL- $1 \alpha$ (Patel et al., 2005). In particular, studies have been performed seeking the relationship between each cytokine with AD.

\section{IL-1}

IL- 1 is known to be able to induce APP- $\beta$ mRNA expression in endothelial cells (Goldgaber et al., 1989), which suggests that IL1 increasing in $\mathrm{AD}$ patients could be linked to $\mathrm{A} \beta$ formation. In a study with $\mathrm{AD}$ patients, it was also proposed that IL-1 was produced by microglial cells surrounding NPs and this cytokine could promote $S 100 \beta$ synthesis in astrocytes (Griffin et al., 1989). Subsequently, it was discovered that IL-1 was a contributing factor to initiate dystrophic neurite formation in $\mathrm{A} \beta$ diffuse deposits (Griffin et al., 1995). Similarly, the exposure of primary cultures of rat cortical neurons to $S 100 \beta$ promotes dystrophic neurite formation and APP- $\beta$ mRNA expression (Li et al., 1998). Thus, IL-1 might promote the $A \beta$ formation and neuronal degeneration through $S 100 \beta$ present in reactive astrocytes. Additionally, the increase in IL-1 in AD patients might promote an increase in p38-MAP kinase activity, which could lead to Tau hyperphosphorilation (Sheng et al., 2000; Li et al., 2003). IL-1 $\beta$ signaling blockade decreases GSK-3 $\beta$ activity and Tau phosphorylation and promotes neurogenesis through the $\mathrm{Wnt} / \beta$-catenin pathway (Kitazawa et al., 2011). However, it has been recently suggested that IL-1 $\beta$ could promote A $\beta$ removal (Matousek et al., 2012).

\section{IL-6}

IL-6 is produced by microglial cells and is involved in the immunoreactivity present in patient tissues with clinical dementia (Hull et al., 1996). Similarly to IL-1, IL-6 promotes APP- $\beta$ expression (Ringheim et al., 1998) and could also contribute to NFT formation by inducing Tau phosphorylation through $\mathrm{cdk} 5 / \mathrm{p} 35$ pathway deregulation (Quintanilla et al., 2004). However, IL-6 overexpression has been observed in the brain of two hAPP transgenic models (TgCRND8 and Tg2576). This overexpression resulted in significant gliosis, a decrease in $A \beta$ deposits in TgCRND8 mice brains due to phagocytic marker upregulation in glial cells and increasing microglial $\mathrm{A} \beta$ phagocytosis. IL-6-induced neuroinflammation, and has not any effect on APP- $\beta$ processing in TgCRND8 mice, which suggests that reactive gliosis, could have a beneficial effect in early stages of disease by promoting $A \beta$ elimination (Chakrabarty et al., 2010).

\section{TNF- $\alpha$}

TNF- $\alpha$ is a cytokine that can have beneficial or harmful effects on different neurons. This cytokine stimulates NF- $\mathrm{B}$ transcription factor which, induces the pro-inflammatory molecules expression, and promote the synthesis of neuronal survival factors such as calbindin, manganese superoxide dismutase enzyme, and anti-apoptotic Bcl-2 protein (Wajant et al., 2003; Kamata et al., 2005). This cytokine can stimulate microglia glutaminase to release glutamate, thus generating excitotoxicity (Takeuchi et al., 2006) and promoting the development of neurodegenerative diseases. In $\mathrm{AD}$, the direct role of this cytokine remains uncertain; however, TNF- $\alpha$ could be associated with an increased $\beta$ - and $\gamma$-secretase enzyme expression (Blasko et al., 2000; Liao et al., 2004). In vitro models have shown that TNF- $\alpha$ directly stimulates BACE1 expression, thus favoring APP processing (Yamamoto et al., 2007). The use of soluble TNF- $\alpha$ inhibitors had a protective effect on APP deregulation by decreasing amyloid aggregate formation and attenuating the cognitive impairment observed in 3xTgAD mice exposed to chronic peripheral inflammation (McAlpine et al., 2009). However, a long-term suppression of the TNF- $\alpha$ receptor signaling pathway can suppress the microglial ability to efficiently remove $A \beta$ aggregates, thus favoring its aggregation at early stages (Montgomery et al., 2011).

\section{TGF- $\beta$}

TGF- $\beta$; is another cytokine with pleiotropic functions, which has an anti-apoptotic function and promotes neuronal survival. It is believed that this cytokine is involved in neurodegenerative diseases (Krieglstein et al., 2002; Konig et al., 2005). It has been reported an increase in TGF- $\beta 1$ levels in the brain of AD patients (Flanders et al., 1995). Animal models (hAPP/TGF- $\beta 1$ ) have shown that TGF- $\beta 1$ overexpression promotes amyloidogenesis in the meninges and cerebral vasculature at early stages (2-3 months) (Wyss-Coray et al., 1997). By contrast, in hAPP/TGF$\beta 1$ transgenic mice parenchyma, there is a decrease in amyloid plaque formation, which correlates with microglial activation (Wyss-Coray et al., 2001). In AD patients, although TGF levels are elevated, there is a significant decrease in the expression of the TGF- $\beta$ receptor type II (T $\beta$ RII); this decrease may suggest that the signaling pathway mediated by this receptor has significant neuroprotective functions and could be altered during the development of the disease (Tesseur et al., 2006).

In summary, the role played by cytokines remains controversial. On one hand, cytokines might favor microglial and astrocytic activation to promote $A \beta$ phagocytosis and neuronal survival. On the other hand, chronic cytokine production has been described as contributors of neurodegeneration. 


\section{CHEMOKINES}

Chemokines are small proteins whose principal function is to attract monocytes, macrophages, lymphocytes, neutrophils, basophils, eosinophils, and dendritic cells toward sites in which an inflammatory response is required. Chemokines function through the activation of their $\mathrm{G}$ protein-coupled receptors and are divided into four families, CXC, CC, C, and $\mathrm{CX}_{3} \mathrm{C}$ (Wells et al., 1998; Cyster, 1999).

Astrocytes and microglial cells, are the main producer of chemokines in the CNS, and their receptors are observed to be present in neurons. Chemokines and their receptors also participate in the CNS immune response and promote lymphocyte migration from the lymphoid organs in order to establish the inflammatory process (Ransohoff et al., 1996).

Evidence of the participation of chemokines in $\mathrm{AD}$ is the presence of monocyte chemotactic proteins (MCP-1 or CCL2) and chemokine receptors CCR3 and CCR5 in reactive microglia that surround senile plaques of $\mathrm{AD}$ patients. By contrast, the macrophage inflammatory protein $1 \alpha(\mathrm{MIP}-1 \alpha)$ is located mainly in neurons, and MIP- $1 \beta$ is located primarily in astrocytes that surround the plaques (Ishizuka et al., 1997; Xia et al., 1998). The differential expression of chemokines and their receptors promotes glia-neuron communication to establish a local inflammatory response, which could favor $A \beta$ phagocytosis in early stages of AD. Similarly, it is known that this inflammation contributes to Tau pathology and thereby accelerates the disease progression (Zilka et al., 2012).

Chronic inflammation in $\mathrm{AD}$ promotes the increased chemotaxis of phagocytic cells, thus favoring microglial recruitment around $A \beta$ aggregates (Yamamoto et al., 2005). A recent study of CSF from AD patients revealed increased CCL2 levels, which correlated with cognitive decline (Westin et al., 2012). Moreover, because of $\mathrm{A} \beta$ aggregation, an increase in IL- 8 production (CXCL8) is generated in neurons, which correlates with an increase in the formation of brain-derived neurotrophic factor (BDNF) (Ashutosh et al., 2011).

The presence of $A \beta$, in the microvasculature, promotes the release of IL-8, MCP-1, MIP-1 MIP-1 $\alpha$, and MIP$1 \beta$ chemokines, and thereby promotes monocyte differentiation into macrophages and their migration through the blood-brain barrier (Fiala et al., 1998). CSF analysis from $\mathrm{AD}$ patients also showed an increase in MCP-1 and IL8 chemokines levels (Galimberti et al., 2003; Correa et al., 2011). Similarly, in vitro models have demonstrated the migration ability of lymphocytes $\left(\mathrm{CD}^{+}\right.$and $\left.\mathrm{CD}^{+}\right)$through the blood-brain barrier (Man et al., 2007) because of an increased MIP- $1 \alpha$ level.

In conclusion, chemokines in the CNS are able to promote local and peripheral immune system cell migration in order to establish an immune response. In $\mathrm{AD}$, it has been proposed that the chronic production of chemokines contributes to disease progression.

\section{CYCLOOXYGENASES}

Cyclooxygenases (COX) are enzymes responsible for converting arachidonic acid to $\mathrm{H} 2$ prostaglandin, which is a PG precursor. In general, these lipidic molecules are involved in inflammation because they cause vasodilation, thus allowing the immune system cell transport to operate at the target site (Williams, 1978). COX-1 and COX-2 isoforms are expressed in mammalian brain. COX-1 is expressed in microglia and neurons located in the pons and spinal cord that perform autonomous and sensory functions. COX-2 occurs in glutamatergic neurons of hippocampus and cortex and is thought to be involved in the modulation of plasticity processes and long-term potentiation (Yamagata et al., 1993; Breder et al., 1995); in pathological conditions, the presence of COX-1 in the CNS has been linked to inflammation development, whereas COX-2 is associated with neurotoxicity. Microglia surrounding the NPs in AD patient shows a high expression of COX-1, which suggests inflammation (Yermakova et al., 1999). On the other hand, COX-2 expression in the hippocampal CA3 region appears to be related with the quantity of NPs and NFTs and the observed cognitive impairment (Ho et al., 2001). COX-2 overexpression in a triple transgenic model (hAPP/PS1/hCOX-2) has resulted in an increase in active Caspase-3 immuoreactivity and retinoblastoma protein phosphorylation $\left(S^{795}-\mathrm{pRb}\right)$. The $\mathrm{Rb}$ protein regulates the $\mathrm{G1}$ phase of the cell cycle, but $S^{725}$ phosphorylation suppresses cell growth. In vitro studies revealed that hCOX-2 overexpression in primary cultures of cortical and hippocampal neurons derived from transgenic mice, accelerates the apoptotic damage induced by $\mathrm{A} \beta$, causing cell cycle abnormalities (Xiang et al., 2002a). COX2 also promotes amyloid plaque formation in parenchyma and increases prostaglandin E2 production. This increased plaque formation, correlates with an increase in amyloid peptide formation (A $\beta 1-40$ and $A \beta 1-42)$ through the $\gamma$-secretase activation without affecting the APP expression levels (Xiang et al., 2002b). Studies performed in a mouse model using $\mathrm{COX}-2^{-/-}$deficient mice demonstrated that the inflammatory response mediated by $\mathrm{A} \beta$ was diminished, which suggested that COX-2 inhibition could be an important target to be use for therapy (Choi and Bosetti, 2009).

The analysis of post-mortem brain tissue from AD patients demonstrated that the maximum immunoreactivity for COX-2 and ppRb occurred in the early stages of the disease (Braak), before occur the maximum astrocytic and microglial activation. Contrary to in vitro observations, the post-mortem tissue analysis did not support the direct relationship between the microglial and astrocytic activation with the neuronal COX-2 and $\mathrm{ppRb}$ expression in $\mathrm{AD}$ (Hoozemans et al., 2005).

Currently, the cause of alterations in COX-2 levels during different stages of $\mathrm{AD}$, remains unknown. However, it has been suggested that inflammation in the early stages of $\mathrm{AD}$ could promote such alterations, and IL- $1 \beta$ could promote an increase in COX-2 expression and PGs production (Hoozemans et al., 2001).

\section{NITRIC OXIDE}

NO is a molecule that contributes importantly in cell signaling. In the presence of oxygen, L-arginine, is converted to Lcitrulline and release NO. Nitric oxide synthase (NOS) is the enzyme responsible for catalyzing this reaction, and it occurs in three isoforms. In the CNS, the neuronal isoform (nNOS) is widely distributed in neurons, astrocytes and blood vessels. 
The endothelial isoform (eNOS) is located in the hippocampal pyramidal neurons, endothelial cells and some astrocytes. The expression of the inducible isoform (iNOS) is typically low but is increased in microglia and astrocytes during neuroinflammation. Under physiological conditions, it is believed that NO regulates the release of neurotransmitters and hormones and promotes cell survival and long-term potentiation. However, high levels of NO are generated in inflammatory conditions, which might contribute to synaptic transmission dysfunction, protein and lipid oxidative damage, excitotoxicity, and neuronal death (Liu et al., 2002; Bishop and Anderson, 2005; Calabrese et al., 2007).

Tissue and neuronal analyses of $\mathrm{AD}$ patients have revealed that $\mathrm{A} \beta$ is able to promote NOS expression and NO production in microglia cells and reactive astrocytes (Goodwin et al., 1997; Wallace et al., 1997; Akama et al., 1998). A $\beta$ also promotes the pro-inflammatory cytokines IL- $1 \beta$ and TNF- $\alpha$ liberation which contribute to $\mathrm{NO}$ and peroxynitrite formation (Rossi and Bianchini, 1996; Combs et al., 2001) and cause protein and lipid modifications, mitochondrial damage, apoptosis and promote $A \beta$ formation, increasing the $\gamma$-secretase complex activity (Torreilles et al., 1999; Keil et al., 2004; Guix et al., 2012). Under normal conditions, NO is synthesized in the microvasculature and regulates $\beta$-secretase activity which participate in APP processing (Austin et al., 2010). NOS2 also favors $A \beta$ elimination by regulating MMP-9/TIMP-1 expression, which is a key enzyme that degrades amyloid (Ridnour et al., 2012). In addition, it has been shown that chronic NO formation may alter insulin-degrading enzyme activity (Kummer et al., 2012). NO synthesis during AD development could also contribute to NFT formation. In co-cultures of astrocytes and hippocampal neurons of rats, exposure to A $\beta 25-35$ was found to increase NO levels, which correlated with increased hyperphosphorylated Tau protein. Interestingly, the use of a NOS inhibitors reduced Tau phosphorylation levels (Saez et al., 2004).

\section{INFLAMMATION MODULATOR TREATMENTS: THERAPEUTICS IN AD}

In the early 1990s, studies began to emerge relating the inflammation process with AD. Studies such as those of Fillit et al. (1991) showed that certain pro-inflammatory cytokines were elevated in AD patients.

Epidemiological studies (Li et al., 1992) indicates that subjects with arthritis have a lower prevalence of $\mathrm{AD}$, after which it was proposed that this negative association could be related to the chronic use of anti-inflammatory drugs (Dickson and Rogers, 1992). From these and other results, these drugs began to be proposed as a new therapeutic approach for AD treatment. Currently, numerous epidemiological studies, experimental in vitro and in vivo models and clinical trials have been designed to elucidate the relationship between modulators of inflammation and AD.

Typically, anti-inflammatory agents are divided into nonsteroidal anti-inflammatory drugs (NSAIDs) and glucocorticoids. This section will review the mechanisms of action of both types of anti-inflammatory agents and their role in $\mathrm{AD}$ and the results of some of the most relevant epidemiological and experimental studies. This section will also analyse the use of active and passive immunotherapy as a therapeutic strategy for AD (Table 1).

\section{ANTI-INFLAMMATORY DRUGS}

NSAIDs are a heterogeneous group of drugs that share a common mechanism of action, which involves COX-1 and COX-2 enzymes inhibition either selectively or non-selectively (Vane and Botting, 1987). These enzymes catalyze arachidonic acid conversion to prostaglandin $\mathrm{H}_{2}\left(\mathrm{PGH}_{2}\right)$, which is subsequently converted into various $\mathrm{PGs}\left(\mathrm{PGE}_{2}, \mathrm{PGD}_{2}, \mathrm{PGF}_{2 \alpha}\right.$, and $\left.\mathrm{PGI}_{2}\right)$ and thromboxane (TX) (Dubois et al., 1998).

PG and TX synthesis increases in occurrence of tissue damage, acting as inflammation mediators, increasing blood flow and vasodilation in the damaged tissue and increasing microvascular permeability (Flower et al., 1976).

The results of several epidemiological studies designed to identify AD risk factors have shown that prolonged use of NSAID could reduce $\mathrm{AD}$ risk. The following are the results from some of the most representative studies conducted on different worldwide populations.

The Sydney Old Persons Study showed that NSAID use, is significantly lower in subjects who developed $\mathrm{AD}$ than in those who did not develop any type of dementia during the study period (Broe et al., 2000). Notably, NSAID use is not associated with any other type of dementia except $\mathrm{AD}$. This result could suggest that NSAID use in AD may act through a different mechanism from their properties as cyclooxygenase inhibitors. The Rotterdam study (In'T Veld et al., 2001), Multi-Institutional Research Alzheimer's Genetic Epidemiology Study (Yip et al., 2005) and Canadian Study of Health and Aging (CSHA) (Coté et al., 2012) also observed an association between the NSAID use and a reduced AD risk. Szekely et al. conducted a meta-analysis of six studies (the Baltimore Longitudinal Study of Aging, Cache County Study, CSHA, Cardiovascular Health Study, Framingham Heart Study and Monongahela Valley Independent Elders Study) and reiterated the association between the NSAID use and a reduced AD risk (Szekely et al., 2008). However, some studies have failed to replicate this association. The Longitudinal Aging Study Amsterdam observed a reduction in $\mathrm{AD}$ risk associated with the use of aspirin alone and observed no association between AD risk and other NSAIDs (Jonker et al., 2003). Bendlin et al. also observed no significant differences in the results of neuropsychological memory and learning tests between NSAIDs users and non-users (Bendlin et al., 2010).

Other studies have observed controversial results, such as Fourrier et al. who observed an association between NSAIDs use and a decrease in Mini-Mental State Examination (MMSE) scores (Fourrier et al., 1996). Similarly, Breitner et al. reported a greater incidence of $\mathrm{AD}$ among NSAIDs users compared with controls (Breitner et al., 2009).

Martin et al. obtained equally unfavorable results when testing the effect of naproxen and celecoxib in older adults with a family history of AD (Martin et al., 2008). In this study, subjects treated with naproxen and those treated with celecoxib scored lower on the MMSE than subjects treated with placebo, which suggested a detrimental effect of the use of these drugs on cognitive performance. Aisen et al. tested the effect of rofecoxib and naproxen 
Table 1 | Inflammation modulator treatments and their effects in animal models and clinical trials.

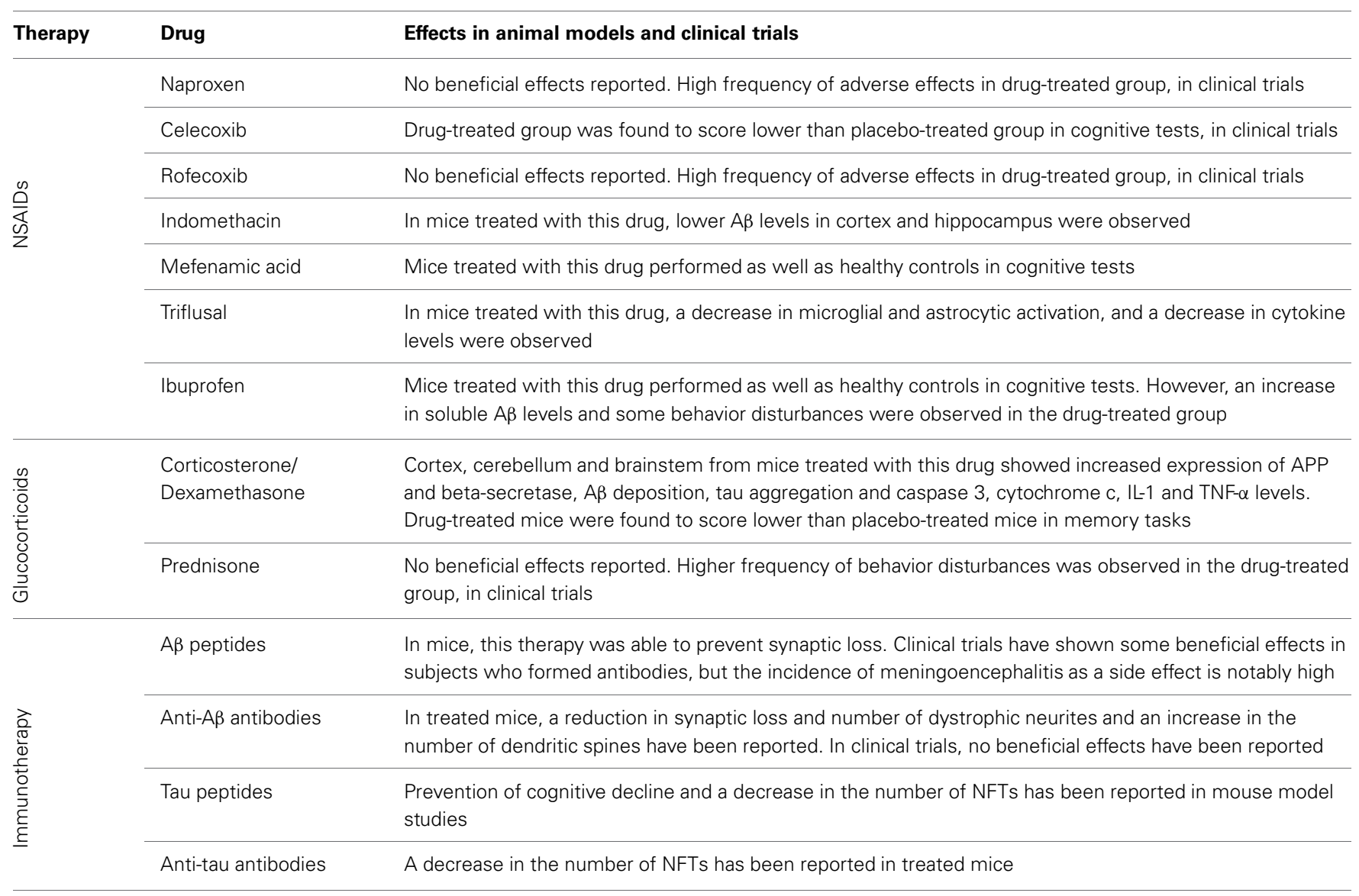

Although most of these treatments have been successful in animal models, these beneficial results have not been reproduced in clinical trials, and even have been cause of detrimental effects.

on patients with mild to moderate AD (Aisen et al., 2003). The study, which lasted one year, showed no significant differences in the performance of subjects treated with rofecoxib or naproxen or placebo. In addition, subjects in NSAID-treated groups reported a high frequency of adverse effects such as fatigue and dizziness and had a significantly higher incidence of hypertension. Another study with rofecoxib, conducted in patients with mild cognitive impairment (MCI), suggested a deleterious effect of rofecoxib (Thal et al., 2005).

The results of $\mathrm{AD}$ animal model studies appear to support the hypothesis that the use of NSAID is beneficial, not only as a method of preventing the disease, but also as a therapeutic strategy. This support was observed in Tg2576 (Swe-APP) transgenic mice treated with indomethacin, which showed a marked decrease in $A \beta$ levels $\left(A \beta_{1-40}\right.$ and $\left.A \beta_{1-42}\right)$ in both cortex and hippocampus (Sung et al., 2004).

Subsequently, Joo et al. showed that mice treated with mefenamic acid for 3 weeks after being treated with $A \beta 1-42$ or expressing Swe-APP, re-established their performance in the Morris water maze test in a comparable way to the vehicle-treated group (Joo et al., 2006). Coma et al. obtained similar results in Tg2576 transgenic mice treated with Triflusal (a NSAID from the salicylate family but a non-aspirin derivative), thus re-establishing transgenic mice $(\mathrm{Tg}+)$ performance in Morris test and a conditioning test (Coma et al., 2010). Although Triflusal had no effect on reducing NP size (NPS) or number, it reduced the amount of activated astrocytes and microglia and IL- $1 \beta$ and TNF- $\alpha$ levels in the hippocampal CA1 region and entorhinal cortex. Van Dam et al. observed similar results in TgAPP23 mice after treatment with Ibuprofen (Van Dam et al., 2010).

In the animal model (5XFAD), which overexpressed the Swedish double mutation (K670N, M671L), Florida mutation (I716V), London mutation (V717I), and double mutation in PS1 (M146L and L286V), treatment with ibuprofen for 3 months resulted in a reduction of the inflammatory response. However, it is notable that there was an increase in soluble $A \beta 42$ levels and there was some changes in behavior, thus questioning whether anti-inflammatory drug use may actually be beneficial for $\mathrm{AD}$ treatment (Hillmann et al., 2012).

Whereas inflammation is a neuropathological feature always present in $\mathrm{AD}$, and inflammatory processes significantly contribute to cell damage in this disease, previous studies performed in vivo and in vitro suggest that NSAIDs participation in $\mathrm{AD}$ occurs not only through an anti-inflammatory mechanism but also by modulating $A \beta$ synthesis and removal in the CNS. Several studies have shown that NSAIDs stimulate the 
non-amyloidogenic APP-processing pathway (Avramovich et al., 2002), decrease $\beta$-secretase levels (Sastre et al., 2006), and reduce the $\mathrm{A} \beta$ formation (Hirohata et al., 2005).

Although animal models appear to show that NSAIDs are a promising therapeutic option, currently, no clinical trials conducted with these drugs have achieved favorable results in $\mathrm{AD}$ patients.

\section{GLUCOCORTICOIDS}

Similar to NSAIDs, glucocorticoids have potent antiinflammatory effects, which have made them strong candidates for $\mathrm{AD}$ treatment. Basically, the mechanism of action of glucocorticoids is based on their ability to bind to its receptors (Glucocoticoid Receptor, GR), which is observed in the cytoplasm in its free form, which translocates into the nucleus after binding to one of its ligands. When GR locate at the nucleus, it binds to certain nucleotide sequences, glucocorticoid response elements (GREs), which are located in the promoter region of a variety of genes.

Depending on the type of GRE sequence to which it binds, GR will positively or negatively regulate gene expression (Beato et al., 1989). The importance of this binding in the inflammatory process is that some genes which GR binds to and activates, have anti-inflammatory effects such as annexin-1 (lipocortin-1),

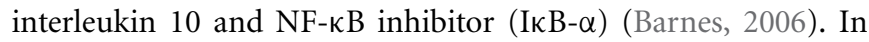
addition, it has also been suggested that glucocorticoids interact directly with $\mathrm{A} \beta$.

The study of post-mortem AD brains showed a decrease in the presence of NPs in subjects under chronic treatment with corticosteroids. No significant differences were observed in the number of NFTs. This study also reported no association between chronic treatment with NSAIDs and the number of NPs (Beeri et al., 2012).

Despite its anti-inflammatory effect, the use of glucocorticoid as a therapeutic strategy in the treatment of $\mathrm{AD}$ is controversial, because numerous studies have associated increased levels of glucocorticoids (cortisol), to an increased AD risk. In 1994, Swaab et al. measured cortisol levels in post-mortem samples of CSF and observed an $83 \%$ increase in AD subjects compared to healthy controls (Swaab et al., 1994). These results coincide with the results of Laske who observed significantly higher levels of serum cortisol in $\mathrm{AD}$ patients compared with age-matched healthy controls (Laske et al., 2009).

The majority of animal model experiments does not support the use of corticosteroids as a therapeutic strategy for $\mathrm{AD}$ and suggests that these drugs promote the development of the neuropathological features of this disease.

The treatment of rats with glucocorticoids (corticosterone and dexamethasone) induces an increase in APP expression in cortex, cerebellum, and brain stem (Budas et al., 1999), thus suggesting an adverse effect. Additionally, there is an increase in $A \beta$ formation because of the increased APP and $\beta$-secretase levels. These glucocorticoid levels also correlate with Tau accumulation (Green et al., 2006), memory, and learning impairment (Yao et al., 2007) and increased levels of caspase 3 and cytochrome c, which indicates the presence of a pro-apoptotic enviroment ( $\mathrm{Li}$ et al., 2010). Finally, high levels of corticosterone in hippocampal cells have a pro-inflammatory effect, thus favoring IL- 1 and TNF- $\alpha$ expression (Macpherson et al., 2005).

These studies indicates that the mechanisms that might associate glucocorticoids with an increase in $\mathrm{AD}$ risk are related with the increasing expression of proteins involved in $\mathrm{A} \beta$ synthesis (APP and $\beta$-secretase) or promoting apoptosis (Cotman and Anderson, 1995).

In humans, there is only one clinical trial investigating the effect of glucocorticoids in the treatment for $\mathrm{AD}$, the trial investigate the used of a daily dose of prednisone or placebo for 1 year (Aisen et al., 2000). There were no significant differences in the cognitive performance of $\mathrm{AD}$ subjects treated with prednisone or placebo at the end of treatment; however, the prednisone-treated subjects showed a higher frequency of behavioral disturbances compared to controls.

In general, there is little evidence to suggest the neuroprotective or therapeutic role of glucocorticoids in $\mathrm{AD}$; in contrast, there is extensive evidence of a possible neurotoxic role. Whereas it is possible that under certain conditions these substances are actually neuroprotective, details of their mechanism of action should be extensively evaluated in $\mathrm{AD}$ before a clinical testing protocol can be considered.

\section{IMMUNOTHERAPY}

Currently, there is no consensus among researchers regarding what triggers $\mathrm{AD}$ pathophysiology or which events are causes and which are bodily responses to counteract the damage caused by the disease. This problem has also been raised regarding inflammation.

Whereas therapies using NSAIDs and glucocorticoids were designed based on the idea that the immune response in $\mathrm{AD}$ has an adverse effect (Blasko et al., 2004) or may be a causal factor (McGeer and McGeer, 1995), there are other approaches which suggest that the immune response may be beneficial because it attempts to counteract the deleterious effects of $A \beta$ oligomers and Tau aggregation.

Immunotherapy is one of the therapeutic strategies designed under these bases because it is underlying on promoting the immune response against the altered molecules that are present in the most distinctive histopathological lesions of the disease (NPs and NFTs) and destroy them. This section will review the types (anti- $\mathrm{A} \beta$ and anti-Tau immunotherapy) and some results of immunotherapeutic studies with $\mathrm{AD}$ patients.

\section{ANTI-A $\beta$ IMMUNOTHERAPY}

Animal studies in which the anti- $\mathrm{A} \beta$ immunotherapy strategy has been tested have been promising. Buttini observed that either active (using four different $A \beta$ sequence fragments) or passive immunotherapy (using 3D6 anti-A $\beta$ and 12B4 antibodies) prevent the loss of synapses in PDAPP transgenic mice (Buttini et al., 2005).

The application of a single 3D6 anti- $\mathrm{A} \beta$ dose in $\mathrm{Tg} 2576$ mice demonstrated that there was no reduction in the number of NPs; nevertheless, there was a reduction in the number of dystrophic neurites (Rozkalne et al., 2009). On the other hand, the application of this antibody in PDAPP mice showed an increase in the number of dendritic spines, which suggests that this anti-A $\beta$ 
immunotherapy approach, can increase neuronal plasticity and could contribute to the recovery of neural circuits. Subsequently, the effect of passive immunotherapy was studied with 7B6 anti$\mathrm{A} \beta$ antibodies in A $\beta$ APPswe/PS1dE9 mice (Spires-Jones et al., 2009; Liu et al., 2011). The authors observed that mice had a higher density of mono-aminergic axons in both the cortex and hippocampus. Immunotherapy using anti-A $\beta$ CAD106 antibodies in different transgenic mouse models for APP (APP23 and APP24) showed a reduction in the presence of $A \beta$ in both models (Wiessner et al., 2011).

In humans, some results suggest that anti-A $\beta$ active immunotherapy could be beneficial; however, the frequency of adverse effects has been too high. In a study of active immunotherapy using $A \beta_{1-42}$ pre-aggregating (AN1792) in combination with immunogenic adjuvant QS-21 (a saponin of vegetable origin) observed a slower cognitive decline in subjects responding to the treatment (forming specific antibodies) (Hock et al., 2003; Orgogozo et al., 2003). However, 10\% of the participants developed cases of aseptic meningoencephalitis. A similar result was obtained in an additional group of patients who were evaluated after stopping the treatment due to the adverse effects observed. The monitoring of these patients included cognitive testing and MRI scans to determine brain volume. Patients who were classified as antibody producers before the suspension of the study were tested for the presence of antibodies using ELISA; $89 \%$ of patients had antibodies at the time of investigation. These patients positive to antibodies production, performed better on cognitive tests than those treated with placebo, which suggests a possible beneficial effect of the treatment. However, brain volume loss was identical for both groups (Vellas et al., 2009).

The high incidence of aseptic meningoencephalitis among the subjects receiving active anti-A $\beta$ immunotherapy could be attributed to an excessive pro-inflammatory response by $\mathrm{T}$ lymphocytes. Unfortunately, passive immunization with bapineuzumab, (a humanized murine monoclonal antibody), showed no differences in cognitive performance in subjects treated with bapineuzumab or placebo (Salloway et al., 2009).

\section{ANTI-Tau IMMUNOTHERAPY}

Most of the research efforts into $\mathrm{AD}$ immunotherapy have focused on anti-A $\beta$ immunotherapy. However, some studies in animal models have also used anti-Tau immunization.

Boutajangout et al. showed that immunotherapy with the complete 441 amino acids peptides of the human Tau protein (hTau) prevented cognitive decline in an hTau transgenic mouse model, which expressed the hTau transgene (Boutajangout et al., 2010). Boimel et al. immunized the Tau transgenic mice presenting NFTs with phosphorylated Tau peptides. A 40\% reduction in the number of NFTs was observed (Boimel et al., 2010). Chai et al. studied the effect of passive immunotherapy for Tau in JNPL3 and P301S transgenic mice. Using PHF1 and MC1 antibodies, the authors observed that the peripheral administration of both antibodies significantly reduced Tau pathology compared to controls (Chai et al., 2011). Although these results suggest that anti-Tau immunotherapy could provide favorable results, no clinical trial has been reported to date that evaluated the real effects on humans.
These results indicate that immunotherapy, particularly anti$\mathrm{A} \beta$ active immunotherapy, could be advantageous when a strategy that minimizes its adverse effects is achieved. Further studies are also required with anti-Tau immunotherapy to evaluate whether this therapy could be functional in the future.

\section{CONCLUSION}

Currently, several genetic and epidemiological studies have provided an overview of the inflammatory mechanisms involved in $\mathrm{AD}$. Although the molecular basis of the disease remains unknown, the inflammation induced by $A \beta$ has an important role in the neurodegenerative process. The inflammatory process itself is driven by microglial and astrocytic activation through the induction of pro-inflammatory molecules and related signaling pathways, thus leading to synaptic damage, neuronal loss, and the activation of other inflammatory participants.

Although, the role of amyloid as a potential initiator of inflammation is not obvious, its accumulation exerts an indirect effect by activating caspases and transcription factors, such as NF- $\mathrm{B}$ and AP-1, which produce numerous inflammation amplifiers (IL-1 $\beta$, TNF- $\alpha$, and IL-6). Pro-inflammatory cytokines, such as TNF- $\alpha$ and IL- $1 \beta$ and IL- 6 , could act directly on the neuron and induce apoptosis. Similarly, TNF- $\alpha$ and IL- $1 \beta$ can activate astrocytes, which could release factors that have the capacity to activate microglia.

Furthermore, APP, BACE1, and PSEN expression is governed by factors such as NF- $\kappa \mathrm{B}$. The genes encoding these proteins have sites in their promoter regions, which are recognized by NF- $\mathrm{B}$; in turn, the expression of these factors is upregulated by the presence of pro-inflammatory cytokines.

Inflammatory mediators acting on neurons contribute to an increase in amyloid production and activate microglia-mediated inflammation. The microglia-neuron communication amplifies the production of factors that contribute to AD-type pathology. However, the neural response is specific for the receptor type expressed in the different neuronal populations. For example, TNF- $\alpha$ binds TNFR1, which activates the cell survival pathway through NF- $\kappa$ B and the apoptotic pathway through the activation of caspases. Conversely, TNFRII signaling only activates NF- $\kappa$ B.

This cascade is primarily mediated by the pro-inflammatory cytokine IL- $1 \beta$, which is expressed by microglia cells. IL- $1 \beta$ may cause neuronal death via various pathways, which activate microglia and consequently increase the release of IL- $1 \beta$, thus generating a self-sustaining mechanism that is amplified by itself. This slow but steady inflammation state, generated for long periods in the brain eventually can destroy neurons and contribute to the clinical symptoms observed in the disease (Figure 1).

Finally, in accordance with all the above data, particularly because the results of the treatments used have been contradictory so far and there are no clinical trials that shown that anti-inflammatory treatments and the use of immunotherapy are completely safe or beneficial, it is necessary to develop and implement new strategies for AD immunological treatments.

\section{ACKNOWLEDGMENTS}

This work was supported by a grant from SEP/CONACYT (No. 157548). 


\section{REFERENCES}

Ager, R. R., Fonseca, M. I., Chu, S. H., Sanderson, S. D., Taylor, S. M., Woodruff, T. M., et al. (2010). Microglial C5aR (CD88) expression correlates with amyloid-beta deposition in murine models of Alzheimer's disease. J. Neurochem. 113, 389-401. doi: 10.1111/j.14714159.2010.06595.x

Aisen, P. S., Davis, K. L., Berg, J. D., Schafer, K., Campbell, K., Thomas, R. G., et al. (2000). A randomized controlled trial of prednisone in Alzheimer's disease. Alzheimer's Disease Cooperative Study. Neurology 54, 588-593. doi: 10.1212/WNL.54.3.588

Aisen, P. S., Schaffer, K. A., Grundman, M., Pfeiffer, E., Sano, M., Davis, K. L., et al. (2003). Effects of rofecoxib or naproxen vs placebo on Alzheimer's Disease progression. a randomized controlled trial. JAMA 289, 2819-2826. doi: 10.1001/jama.289.21.2819

Akama, K. T., Albanese, C., Pestell, R. G., and Van Eldik, L. J. (1998). Amyloid beta-peptide stimulates nitric oxide production in astrocytes through an NFkappaBdependent mechanism. Proc. Natl. Acad. Sci. U.S.A. 95, 5795-5800. doi: 10.1073/pnas.95.10.5795

Akiyama, H., Barger, S., Barnum, S., Bradt, B., Bauer, J., Cole, G. M., et al. (2000). Inflammation and Alzheimer's disease. Neurobiol. Aging 21, 383-421. doi: 10.1016/S0197-4580(00)00124-X

Akiyama, H., Kondo, H., Mori, H., Kametani, F., Nishimura, T., Ikeda, K., et al. (1996). The aminoterminally truncated forms of amyloid beta-protein in brain macrophages in the ischemic lesions of Alzheimer's disease patients. Neurosci. Lett. 219, 115-118. doi: 10.1016/S0304-3940(96)13197-9

Ashutosh, Kou, W., Cotter, R., Borgmann, K., Wu, L., Persidsky, R., et al. (2011). CXCL8 protects human neurons from amyloid-beta-induced neurotoxicity: relevance to Alzheimer's disease. Biochem. Biophys. Res. Commun. 412, 565-571. doi: 10.1016/j.bbrc.2011.07.127

Austin, S. A., Santhanam, A. V., and Katusic, Z. S. (2010). Endothelial nitric oxide modulates expression and processing of amyloid precursor protein. Circ. Res. 107, 1498-1502. doi: 10.1161/CIRCRESAHA.110.233080

Avramovich, J., Amit, T., and Youdim, M. B. H. (2002). Non-steroidal anti-inflammatory drugs stimulate secretion of on-amyloidogenic precursor protein. J. Biol. Chem. 277, 31466-31473. doi: 10.1074/jbc.M201308200

Barnes, P. J. (2006). How corticosteroids control inflammation: quintiles prize lecture 2005. Br. J. Pharmacol. 148, 245-254. doi: 10.1038/sj.bjp.0706736

Beato, M., Chalepakis, G., Schauer, M., and Slater, E. P. (1989). DNA regulatory elements for steroid hormones. J. Steroid Biochem. 32, 737-747. doi: 10.1016/0022-4731(89)90521-9

Beeri, M. S., Schmeidler, J., Lesser, G. T., Maroukian, M., West, R., Leung, S., et al. (2012). Corticosteroids, but not NSAIDs, are associated with less Alzheimer neuropathology. Neurobiol. Aging 33, 1258-1264. doi: $\quad 10.1016 /$ j.neurobiolaging. 2011.02.011

Bendlin, B. B., Newman, L. M., Ries, M. L., Puglielli, L., Carlsson, C. M., Sager, M. A., et al. (2010). NSAIDs may protect against agerelated brain atrophy. Front. Aging Neurosci. 2, 1-8. doi: 10.3389/fnagi.2010.00035

Bishop, A., and Anderson, J. E. (2005). NO signaling in the CNS: from the physiological to the pathological. Toxicology 208, 193-205. doi: 10.1016/j.tox.2004.11.034

Blasko, I., Stampfer-Kountchev, M., Robatscher, P., Veerhuis, R., Eikelenboom, P., and GrubeckLoebenstein, B. (2004). How chronic inflammation can affect the brain and support the development of Alzheimer's disease in old age: the role of microglia and astrocytes. Aging Cell 3, 169-176. doi: 10.1111/j.1474-9728.2004.00101.x

Blasko, I., Veerhuis, R., StampferKountchev, M., Saurwein-Teissl, M., Eikelenboom, P., and Grubeck-Loebenstein, B. (2000). Costimulatory effects of interferongamma and interleukin-1beta or tumor necrosis factor alpha on the synthesis of Abeta1-40 and Abeta1-42 by human astrocytes. Neurobiol. Dis. 7, 682-689. doi: $10.1006 /$ nbdi.2000.0321

Blum-Degen, D., Muller, T., Kuhn, W., Gerlach, M., Przuntek, H., and Riederer, P. (1995). Interleukin1 beta and interleukin-6 are elevated in the cerebrospinal fluid of Alzheimer's and de novo Parkinson's disease patients. Neurosci. Lett. 202, 17-20. doi: 10.1016/0304-3940(95)12192-7

Boimel, M., Grigoriadis, N., Lourbopoulos, A., Haber, E., Abramsky, O., and Rosenmann, H. (2010). Efficacy and safety of immunization with phosphorylated tau against neurofibrillary tangles in mice. Exp. Neurol. 224, 472-485. doi: 10.1016/j.expneurol.2010.05.010

Boutajangout, A., Quartermain, D., and Sigurdsson, E. M. (2010). Immunotherapy targeting pathological tau prevents cognitive decline in a new tangle mouse model. J. Neurosci. 30, 16559-16566. doi: 10.1523/JNEUROSCI.4363-10.2010

Breder, C. D., Dewitt, D., and Kraig, R. P. (1995). Characterization of inducible cyclooxygenase in rat brain. J. Comp. Neurol. 355, 296-315. doi: 10.1002/cne.903550208

Breitner, J. C. S., Haneuse, S. J. P. A., Walker, R., Dublin, S., Crane, P. K., Gray, S. L., et al. (2009). Risk of dementia and $\mathrm{AD}$ with prior exposure to NSAIDs in an elderly community-based cohort. Neurology 72, 1899-1905. doi: 10.1212/WNL.0b013e3181a18691

Broe, G. A., Grayson, D. A., Creasey, H. M., Waite, L. M., Casey, B. J., Bennett, H. P., et al. (2000). Antiinflammatory drugs protect against Alzheimer's Disease at low doses. Arch. Neurol. 57, 1586-1591. doi: 10.1001/archneur.57.11.1586

Budas, G., Coughlan, C. M., Seckl, J. R., and Breen, K. C. (1999). The effect of corticosteroids on amyloid $\beta$ precursor protein/amyloid precursor-like protein expression and processing in vivo. Neurosci. Lett. 276, 61-64. doi: 10.1016/S0304-3940(99)00790-9.

Buttini, M., Masliah, E., Barbour, R., Grajeda, H., Motter, R., Johnson-Wood, K., et al. (2005). Beta-amyloid immunotherapy prevents synaptic degeneration in a mouse model of Alzheimer's disease. J. Neurosci. 25, 9096-9101. doi: 10.1523/ JNEUROSCI.1697-05.2005

Calabrese, V., Mancuso, C., Calvani, M., Rizzarelli, E., Butterfield, D. A., and Stella, A. M. (2007). Nitric oxide in the central nervous system: neuroprotection versus neurotoxicity. Nat. Rev. Neurosci. 8, 766-775. doi: 10.1038/nrn2214

Carrero, I., Gonzalo, M. R., Martin, B., Sanz-Anquela, J. M., ArevaloSerrano, J., and Gonzalo-Ruiz, A. (2012). Oligomers of beta-amyloid protein (Abeta1-42) induce the activation of cyclooxygenase-2 in astrocytes via an interaction with interleukin-1beta, tumour necrosis factor-alpha, and a nuclear factor kappa-B mechanism in the rat brain. Exp. Neurol. 236, 215-227. doi: 10.1016/j.expneurol.2012.05.004
Coma, M., Serenó, L., Da RochaSouto, B., Scotton, T. C., España, J., Sánchez, M. B., et al. (2010). Triflusal reduces dense-core plaque load, associated axonal alterations and inflammatory changes, and rescues cognition in a transgenic mouse model of Alzheimer's disease. Neurobiol. Dis. 38, 482-491.

Combs, C. K., Karlo, J. C., Kao, S. C., and Landreth, G. E. (2001). beta-Amyloid stimulation of microglia and monocytes results in TNFalpha-dependent expression of inducible nitric oxide synthase and neuronal apoptosis. J. Neurosci. 21, 1179-1188.

Correa, J. D., Starling, D., Teixeira, A. L., Caramelli, P., and Silva, T. A. (2011). Chemokines in CSF of Alzheimer's disease patients. Arq. Neuropsiquiatr. 69, 455-459. doi: 10.1590/S0004282X2011000400009

Coté, S., Carmichael, P.-H., Verrault, R., Lindsay, J., Lefebvre, J., and Laurin, D. (2012). Nonsteroidal anti-inflammatory drug use and the risk of cognitive impairment and Alzheimer's disease. Alzheimers Dement. 8, 219-226. doi: 10.1016/j.jalz.2011.03.012

Cotman, C., and Anderson, A. (1995). A potential role for apoptosis in neurodegeneration and Alzheimer's disease. Mol. Neurobiol. 10, 19-45. doi: 10.1007/BF02740836

Cyster, J. G. (1999). Chemokines and cell migration in secondary lymphoid organs. Science 286, 2098-2102. doi: 10.1126/science.286.5447.2098

Chai, X., Wu, S., Murray, T. K., Kinley, R., Cella, C. V., Sims, H., et al. (2011). Passive immunization with anti-tau antibodies in two transgenic models reduction of tau pathology and delay of disease progression. J. Biol. Chem. 286, 34457-34467. doi: 10.1074/jbc.M111.229633

Chakrabarty, P., Jansen-West, K., Beccard, A., Ceballos-Diaz, C., Levites, Y., Verbeeck, C., et al. (2010). Massive gliosis induced by interleukin-6 suppresses Abeta deposition in vivo: evidence against inflammation as a driving force for amyloid deposition. FASEB J. 24, 548-559. doi: 10.1096/fj.09-141754 Chartier-Harlin, M. C., Crawford, F., Hamandi, K., Mullan, M., Goate, A., Hardy, J., et al. (1991). Screening for the beta-amyloid precursor protein mutation (APP717: Val-Ile) in extended pedigrees with early onset Alzheimer's disease. Neurosci. Lett. 129, 134-135. doi: 10.1016/03043940(91)90738-F 
Chibnik, L. B., Shulman, J. M., Leurgans, S. E., Schneider, J. A., Wilson, R. S., Tran, D., et al. (2011). CR1 is associated with amyloid plaque burden and age-related cognitive decline. Ann. Neurol. 69, 560-569. doi: 10.1002/ana.22277

Choi, S. H., and Bosetti, F. (2009). Cyclooxygenase-1 null mice show reduced neuroinflammation in response to beta-amyloid. Aging 1, 234-244.

Desai, M. K., Guercio, B. J., Narrow, W. C., and Bowers, W. J. (2011). An Alzheimer's disease-relevant presenilin-1 mutation augments amyloid-beta-induced oligodendrocyte dysfunction. Glia 59, 627-640. doi: 10.1002/glia.21131

Dickson, D. W., Farlo, J., Davies, P., Crystal, H., Fuld, P., and Yen, S. H. (1988). Alzheimer's disease. a double-labeling immunohistochemical study of senile plaques. Am. J. Pathol. 132, 86-101.

Dickson, D. W., and Rogers, J. (1992). Neuroimmunology of Alzheimer's Disease: a conference report. Neurobiol. Aging 13, 793-798. doi: 10.1016/0197-4580(92)90104-6

Dubois, R. N., Abramson, S. B., Crofford, L., Gupta, R. A., Simon, L. S., Van De Putte, L. B. A., et al. (1998). Cyclooxygenase in biology and disease. FASEB J. 12, 1063-1073.

Duff, K., Eckman, C., Zehr, C., Yu, X., Prada, C. M., Perez-Tur, J., et al. (1996). Increased amyloidbeta42(43) in brains of mice expressing mutant presenilin 1. Nature 383, 710-713. doi: 10.1038/383710a0

El Khoury, J., Hickman, S. E., Thomas, C. A., Loike, J. D., and Silverstein, S. C. (1998). Microglia, scavenger receptors, and the pathogenesis of Alzheimer's disease. Neurobiol. Aging 19, S81-S84. doi: 10.1016/S0197-4580(98)00036-0

Fan, R., Defilippis, K., and Van Nostrand, W. E. (2007). Induction of complement proteins in a mouse model for cerebral microvascular a beta deposition. J. Neuroinflammation 4, 22. doi: 10.1186/1742-2094-4-22

Fiala, M., Zhang, L., Gan, X., Sherry, B., Taub, D., Graves, M. C., et al. (1998). Amyloid-beta induces chemokine secretion and monocyte migration across a human bloodbrain barrier model. Mol. Med. 4, 480-489.

Fillit, H., Ding, W., Buee, L., Kalman, J., Alstiel, L., Lawlor, B., et al. (1991). Elevated circulating tumor necrosis factor levels in Alzheimer's disease.
Neurosci. Lett. 129, 318-320. doi: 10.1016/0304-3940(91)90490-K

Flanders, K. C., Lippa, C. F., Smith, T. W., Pollen, D. A., and Sporn, M. B. (1995). Altered expression of transforming growth factor-beta in Alzheimer's disease. Neurology 45, 1561-1569. doi: 10.1212/WNL.45.8.1561

Flower, R. J., Harvey, E. A and Kingston, W. P. (1976). Inflammatory effects of prostaglandin D2 in rat and human skin. Br. J. Pharmacol. 56, 229-233. doi: 10.1111/j.14765381.1976.tb07446.x

Fonseca, M. I., Ager, R. R., Chu, S. H., Yazan, O., Sanderson, S. D., Laferla, F. M., et al. (2009). Treatment with a $\mathrm{C} 5 \mathrm{aR}$ antagonist decreases pathology and enhances behavioral performance in murine models of Alzheimer's disease. J. Immunol. 183, 1375-1383. doi: 10.4049/jimmunol.0901005

Fonseca, M. I., Zhou, J., Botto, M., and Tenner, A. J. (2004). Absence of $\mathrm{Clq}$ leads to less neuropathology in transgenic mouse models of Alzheimer's disease. J. Neurosci. 24, 6457-6465. doi: 10.1523/ JNEUROSCI.0901-04.2004

Forneris, F., Wu, J., and Gros, P. (2012). The modular serine proteases of the complement cascade. Curr. Opin. Struct. Biol. 22, 333-341. doi: 10.1016/ j.sbi.2012.04.001

Fourrier, A., Letenneur, L., Bégaud, B., and Dartigues, J. F. (1996). Nonsteroidal anti-inflammatory drug use and cognitive function in the elderly: inconclusive results from a population.based cohort study. J. Clin. Epidmiol. 49, 1201. doi: 10.1016/0895-4356(96) 00202-8

Frackowiak, J., Wisniewski, H. M., Wegiel, J., Merz, G. S., Iqbal, K., and Wang, K. C. (1992). Ultrastructure of the microglia that phagocytose amyloid and the microglia that produce beta-amyloid fibrils. Acta Neuropathol. 84, 225-233. doi: 10.1007/BF00227813

Galimberti, D., Schoonenboom, N., Scarpini, E., and Scheltens, P. (2003). Chemokines in serum and cerebrospinal fluid of Alzheimer's disease patients. Ann. Neurol. 53, 547-548. doi: 10.1002/ana.10531

Gate, D., Rezai-Zadeh, K., Jodry, D., Rentsendorj, A., and Town, T. (2010). Macrophages in Alzheimer's disease: the blood-borne identity. J. Neural Transm. 117, 961-970. doi: 10.1007/s00702-010-0422-7

Glenner, G. G., Wong, C. W., Quaranta, V., and Eanes, E. D. (1984). The amyloid deposits in Alzheimer's disease: their nature and pathogenesis. Appl. Pathol. 2, 357-369.

Goate, A., Chartier-Harlin, M. C., Mullan, M., Brown, J., Crawford, F., Fidani, L., et al. (1991). Segregation of a missense mutation in the amyloid precursor protein gene with familial Alzheimer's disease. Nature 349, 704-706. doi: 10.1038/349704a0

Goldgaber, D., Harris, H. W., Hla, T. Maciag, T., Donnelly, R. J., Jacobsen, J. S., et al. (1989). Interleukin 1 regulates synthesis of amyloid betaprotein precursor mRNA in human endothelial cells. Proc. Natl. Acad. Sci. U.S.A. 86, 7606-7610. doi: 10.1073/pnas.86.19.7606

Goodwin, J. L., Kehrli, M. E. Jr., and Uemura, E. (1997). Integrin Mac1 and beta-amyloid in microglial release of nitric oxide. Brain Res. 768, 279-286. doi: 10.1016/S00068993(97)00653-7

Green, K. N., Billings, L. M., Roozendaal, B., McGaugh, J. L., and Laferla, F. M. (2006). Glucocorticoids increase amyloid-beta and tau pathology in a mouse model of Alzheimer's disease. J. Neurosci. 26, 9047-9056. doi: 10.1523/ JNEUROSCI.2797-06.2006

Griffin, W. S., Sheng, J. G., Roberts, G. W., and Mrak, R. E. (1995). Interleukin-1 expression in different plaque types in Alzheimer's disease: significance in plaque evolution. J. Neuropathol. Exp. Neurol. 54, 276-281. doi: 10.1097/00005072199503000-00014

Griffin, W. S., Stanley, L. C., Ling, C., White, L., Macleod, V., Perrot, L. J., et al. (1989). Brain interleukin 1 and S-100 immunoreactivity are elevated in Down syndrome and Alzheimer disease. Proc. Natl. Acad. Sci. U.S.A. 86, 7611-7615. doi: 10.1073/pnas.86.19.7611

Guix, F. X., Wahle, T., Vennekens, K., Snellinx, A., Chavez-Gutierrez, L., Ill-Raga, G., et al. (2012). Modification of gamma-secretase by nitrosative stress links neuronal ageing to sporadic Alzheimer's disease. EMBO Mol. Med. 4, 660-673. doi: 10.1002/emmm.201200243

Haga, S., Ikeda, K., Sato, M., and Ishii, T. (1993). Synthetic Alzheimer amyloid beta/A4 peptides enhance production of complement $\mathrm{C} 3$ component by cultured microglial cells. Brain Res. 601, 88-94. doi: 10.1016/0006-8993(93)91698-R

Halassa, M. M., and Haydon, P. G. (2010). Integrated brain circuits: astrocytic networks modulate neuronal activity and behavior. Annu. Rev. Physiol. 72, 335-355. doi 10.1146/annurev-physiol-021909135843

Henneberger, C., Papouin, T., Oliet, S. H., and Rusakov, D. A. (2010). Long-term potentiation depends on release of D-serine from astrocytes. Nature 463, 232-236. doi: 10.1038 /nature08673

Hillmann, A., Hahn, S., Schilling, S., Hoffmann, T., Demuth, H.U., Bulic, B., et al. (2012). No improvement after chronic ibuprofen treatment in the 5XFAD mouse model of Alzheimer's disease. Neurobiol. Aging 33, 833.e39-833.e50. doi: $10.1016 /$ j. neurobiolaging.2011.08.006

Hirohata, M., Ono, K., Naiki, H., and Yamada, M. (2005). Nonsteroidal anti-inflammatory drugs have anti-amyloidogenic effects for Alzheimer's ß-amyloid fibrils in vitro. Neuropharmacology 49, 1088-1099. doi: 10.1016/ j.neuropharm.2005.07.004

Ho, L., Purohit, D., Haroutunian, V., Luterman, J. D., Willis, F., Naslund, J., et al. (2001). Neuronal cyclooxygenase 2 expression in the hippocampal formation as a function of the clinical progression of Alzheimer disease. Arch. Neurol. 58, 487-492. doi: 10.1001/archneur.58.3.487

Hock, C., Konietzko, U., Streffer, J. R., Tracy, J., Signorell, A., Muller-Tillmanns, B., et al. (2003). Antibodies against Bamyloid slow cognitive decline in Alzheimer's disease. Neuron 38, 547-554. doi: 10.1016/ S0896-6273(03)00294-0

Hoozemans, J. J., Van Haastert, E. S., Veerhuis, R., Arendt, T., Scheper, W., Eikelenboom, P., et al. (2005). Maximal COX-2 and ppRb expression in neurons occurs during early Braak stages prior to the maximal activation of astrocytes and microglia in Alzheimer's disease. J. Neuroinflammation 2, 27. doi: 10.1186/1742-2094-2-27

Hoozemans, J. J., Veerhuis, R., Janssen, I., Rozemuller, A. J., and Eikelenboom, P. (2001). Interleukin-lbeta induced cyclooxygenase 2 expression and prostaglandin E2 secretion by human neuroblastoma cells: implications for Alzheimer's disease. Exp. Gerontol. 36, 559-570. doi: 10.1016/ S0531-5565(00)00226-6

Hull, M., Berger, M., Volk, B., and Bauer, J. (1996). Occurrence of interleukin-6 in cortical plaques of Alzheimer's disease patients may precede transformation of diffuse into neuritic plaques. Ann. N.Y. Acad. Sci. 777, 205-212. 
doi: $\quad$ 10.1111/j.1749-6632.1996. tb34420.x

In'T Veld, B. A., Ruitenberg, A., Hofman, A., Launer, L., Van Duijn, C. M., Stijnen, T., et al. (2001). Nonsteroidal antiinflammatory drugs and the risk of Alzheimer's Disease. $N$. Eng. J. Med. 345, 1515-1521. doi: 10.1056/NEJMoa010178

Ishizuka, K., Kimura, T., Igata-Yi, R., Katsuragi, S., Takamatsu, J., and Miyakawa, T. (1997). Identification of monocyte chemoattractant protein-1 in senile plaques and reactive microglia of Alzheimer's disease. Psychiatry Clin. Neurosci. 51, 135-138. doi: 10.1111/j.14401819.1997.tb02375.x

Iversen, L. L., Mortishire-Smith, R. J., Pollack, S. J., and Shearman, M. S. (1995). The toxicity in vitro of betaamyloid protein. Biochem. J. $311(\mathrm{Pt}$ 1), 1-16.

Jiang, H., Hampel, H., Prvulovic, D., Wallin, A., Blennow, K., Li, R., et al. (2011). Elevated CSF levels of TACE activity and soluble TNF receptors in subjects with mild cognitive impairment and patients with Alzheimer's disease. Mol. Neurodegener. 6, 69. doi: 10.1186/1750-1326-6-69

Jonker, C., Comijs, H. C., and Smit, J. H. (2003). Does aspirin or other NSAIDs reduce the risk of cognitive decline in elderly persons? Results from a populationbased study. Neurobiol. Aging 24, 583-588. doi: 10.1016/ S0197-4580(02)00188-4

Joo, Y., Kim, H.-S., Woo, R.-S., Park, C. H., Shin, K.-Y., Lee, J.-P., et al. (2006). Mefenamic acid shows neuroprotective effects and improves cognitive impairment in in vitro and in vivo Alzheimer's Disease models. Mol. Pharmacol. 69, 76-84.

Kamata, H., Honda, S., Maeda, S., Chang, L., Hirata, H., and Karin, M. (2005). Reactive oxygen species promote TNFalpha-induced death and sustained JNK activation by inhibiting MAP kinase phosphatases. Cell 120, 649-661. doi: 10.1016/j.cell.2004.12.041

Kang, J., Lemaire, H. G., Unterbeck, A., Salbaum, J. M., Masters, C. L., Grzeschik, K. H., et al. (1987). The precursor of Alzheimer's disease amyloid A4 protein resembles a cell-surface receptor. Nature 325, 733-736. doi: $10.1038 / 325733 \mathrm{a} 0$

Keil, U., Bonert, A., Marques, C. A., Scherping, I., Weyermann, J., Strosznajder, J. B., et al. (2004). Amyloid beta-induced changes in nitric oxide production and mitochondrial activity lead to apoptosis. J. Biol. Chem. 279, 50310-50320. doi: 10.1074/jbc.M405600200

Kitazawa, M., Cheng, D., Tsukamoto, M. R., Koike, M. A., Wes, P. D., Vasilevko, V., et al. (2011). Blocking IL-1 signaling rescues cognition, attenuates tau pathology, and restores neuronal beta-catenin pathway function in an Alzheimer's disease model. J. Immunol. 187, 6539-6549. doi: 10.4049/jimmunol.1100620

Kitazawa, M., Yamasaki, T. R., and Laferla, F. M. (2004). Microglia as a potential bridge between the amyloid beta-peptide and tau. Ann. N.Y. Acad. Sci. 1035, 85-103. doi: 10.1196/annals.1332.006

Kobayashi, K., Hayashi, M., Nakano, H., Fukutani, Y., Sasaki, K., Shimazaki, M., et al. (2002). Apoptosis of astrocytes with enhanced lysosomal activity and oligodendrocytes in white matter lesions in Alzheimer's disease. Neuropathol. Appl. Neurobiol. 28, 238-251. doi: 10.1046/ j.1365-2990.2002.00390.x

Konig, H. G., Kogel, D., Rami, A., and Prehn, J. H. (2005). TGF\{beta\} 1 activates two distinct type I receptors in neurons: implications for neuronal NF-\{kappa\}B signaling. J. Cell Biol. 168, 1077-1086. doi: 10.1083/jcb.200407027

Krieglstein, K., Strelau, J., Schober, A., Sullivan, A., and Unsicker, K. (2002). TGF-beta and the regulation of neuron survival and death. J. Physiol. Paris 96, 25-30. doi: 10.1016/ S0928-4257(01)00077-8

Kummer, M. P., Hulsmann, C., Hermes, M., Axt, D., and Heneka, M. T. (2012). Nitric oxide decreases the enzymatic activity of insulin degrading enzyme in APP/PS1 mice. J. Neuroimmune Pharmacol. 7, 165-172. doi: 10.1007/s11481-011-9339-7

Laske, C., Stransky, E., Fritsche, A., Eschweiler, G., and Leyhe, T. (2009). Inverse association of cortisol serum levels with T-tau, P-tau 181 and Ptau 231 peptide levels and T-tau/A $\beta$ 1-42 ratios in CSF in patients with mild Alzheimer's disease dementia. Eur. Arch. Psychiatry Clin. Neurosci. 259, 80-85. doi: 10.1007/s00406008-0838-3

Levy-Lahad, E., Wijsman, E. M., Nemens, E., Anderson, L., Goddard, K. A., Weber, J. L., et al. (1995). A familial Alzheimer's disease locus on chromosome 1. Science 269, 970-973. doi: $10.1126 /$ science.7638621
Li, G., Shen, Y. C., Li, Y. T., Chen, C. H., Zhau, Y. W., and Silverman, J. M. (1992). A case-control study of Alzheimer's disease in China. Neurology 42, 1481-1488. doi: 10.1212/WNL.42.8.1481

Li, W.-Z., Li, W.-P., Yao, Y.-Y., Zhang, W., Yin, Y.-Y., Wu, G.C., et al. (2010). Glucocorticoids increase impairments in learning and memory due to elevated amyloid precursor protein expression and neuronal apoptosis in 12-month old mice. Eur. J. Pharmacol. 628, 108-115. doi: 10.1016/j.ejphar.2009.11.045

Li, Y., Liu, L., Barger, S. W., and Griffin, W. S. (2003). Interleukin-1 mediates pathological effects of microglia on tau phosphorylation and on synaptophysin synthesis in cortical neurons through a $\mathrm{p} 38$-MAPK pathway. J. Neurosci. 23, 1605-1611.

Li, Y., Wang, J., Sheng, J. G., Liu, L., Barger, S. W., Jones, R. A., et al. (1998). S100 beta increases levels of beta-amyloid precursor protein and its encoding mRNA in rat neuronal cultures. J. Neurochem. 71, 1421-1428. doi: 10.1046/j.14714159.1998.71041421.x

Liao, Y. F., Wang, B. J., Cheng, H. T., Kuo, L. H., and Wolfe, M. S. (2004). Tumor necrosis factor-alpha, interleukinlbeta, and interferon-gamma stimulate gamma-secretasemediated cleavage of amyloid precursor protein through a JNKdependent MAPK pathway. J. Biol. Chem. 279, 49523-49532. doi: 10.1074/jbc.M402034200

Liu, B., Gao, H. M., Wang, J. Y., Jeohn, G. H., Cooper, C. L., and Hong, J. S. (2002). Role of nitric oxide in inflammation-mediated neurodegeneration. Ann. N.Y. Acad. Sci. 962, 318-331. doi: 10.1111/j.17496632.2002.tb04077.x

Liu, Y., Lee, M. K., James, M. M., Price, D. L., Borchelt, D. R., Troncoso, J. C., et al. (2011). Passive (Amyloid- $\beta$ Immunotherapy Attenuates Monoaminergic Axonal Degeneration in the A 3 PPswe/PS1dE9 Mice. J. Alzheimer's Dis. 23, 271-279.

Lue, L. F., Rydel, R., Brigham, E. F., Yang, L. B., Hampel, H., Murphy, G. M. Jr., et al., (2001). Inflammatory repertoire of Alzheimer's disease and nondemented elderly microglia in vitro. Glia 35, 72-79. doi: 10.1002/glia.1072

Macpherson, A., Dinkel, K., and Sapolsky, R. (2005). Glucocorticoids worsen excitotoxin-induced expression of pro-inflammatory cytokines in hippocampal cultures.
Exp. Neurol. 194, 376-383. doi: 10.1016/j.expneurol.2005.02.021

Maier, M., Peng, Y., Jiang, L., Seabrook, T. J., Carroll, M. C., and Lemere, C. A. (2008). Complement C3 deficiency leads to accelerated amyloid beta plaque deposition and neurodegeneration and modulation of the microglia/macrophage phenotype in amyloid precursor protein transgenic mice. J. Neurosci. 28, 6333-6341. doi: 10.1523/JNEUROSCI.0829-08.2008

Man, S. M., Ma, Y. R., Shang, D. S., Zhao, W. D., Li, B., Guo, D. W., et al. (2007). Peripheral T cells overexpress MIP-1alpha to enhance its transendothelial migration in Alzheimer's disease. Neurobiol. Aging 28, 485-496. doi: 10.1016/j. neurobiolaging.2006.02.013

Martin, B., Szekely, C., Brandt, J., Piantadosi, S., Breitner, J., Craft, S., et al. (2008). Cognitive function over time in the Alzheimer's Disease Anti-inflammatory Prevention Trial (ADAPT): results of a randomized, controlled trial of naproxen and celecoxib. Arch. Neurol. 65, 896. doi: 10.1001/archneur.2008.65.7.nct70006

Matousek, S. B., Ghosh, S., Shaftel, S. S., Kyrkanides, S., Olschowka, J. A., and O'Banion, M. K. (2012). Chronic IL-1beta-mediated neuroinflammation mitigates amyloid pathology in a mouse model of Alzheimer's disease without inducing overt neurodegeneration. J. Neuroimmune Pharmacol. 7, 156-164. doi: 10.1007/s11481-011-9331-2

McAlpine, F. E., Lee, J. K., Harms, A. S., Ruhn, K. A., Blurton-Jones, M., Hong, J., et al. (2009). Inhibition of soluble TNF signaling in a mouse model of Alzheimer's disease prevents pre-plaque amyloid-associated neuropathology. Neurobiol. Dis. 34, 163-177. doi: 10.1016/j.nbd.2009.01.006

McGeer, P. L., Akiyama, H., Itagaki, S., and McGeer, E. G. (1989). Activation of the classical complement pathway in brain tissue of Alzheimer patients. Neurosci. Lett. 107, 341-346. doi: 10.1016/03043940(89)90843-4

McGeer, P. L., Itagaki, S., and McGeer, E. G. (1988). Expression of the histocompatibility glycoprotein HLA-DR in neurological disease. Acta Neuropathol. 76, 550-557. doi: 10.1007/BF00689592

McGeer, P. L., and McGeer, E. G. (1995). The inflammatory response system of brain: implications for therapy of Alzheimer and other neurodegenerative diseases. 
Brain Res. Rev. 21, 195-218. doi: 10.1016/0165-0173(95)00011-9

Meda, L., Baron, P., Prat, E., Scarpini, E., Scarlato, G., Cassatella, M. A., et al. (1999). Proinflammatory profile of cytokine production by human monocytes and murine microglia stimulated with beta-amyloid[25-35]. J. Neuroimmunol. 93, 45-52. doi: 10.1016/S0165-5728(98)00188-X

Medeiros, R., and Laferla, F. M. (2013). Astrocytes: conductors of the Alzheimer disease neuroinflammatory symphony. Exp. Neurol. 239, 133-138. doi: 10.1016/j.expneurol.2012.10.007

Montgomery, S. L., Mastrangelo, M. A., Habib, D., Narrow, W. C., Knowlden, S. A., Wright, T. W., et al. (2011). Ablation of TNF-RI/RII expression in Alzheimer's disease mice leads to an unexpected enhancement of pathology: implications for chronic pan-TNF-alpha suppressive therapeutic strategies in the brain. Am. J. Pathol. 179, 2053-2070. doi: 10.1016/j.ajpath.2011.07.001

Moynagh, P. N. (2005). The interleukin-1 signalling pathway in astrocytes: a key contributor to inflammation in the brain. J. Anat. 207, 265-269. doi: 10.1111/j.1469-7580.2005.00445.x

Mrak, R. E. (2012). Microglia in Alzheimer brain: a neuropathological perspective. Int. J. Alzheimers Dis. 2012, 165021. doi: 10.1155/ 2012/165021

Mrak, R. E., and Griffin, W. S. (2005). Potential inflammatory biomarkers in Alzheimer's disease. J. Alzheimers Dis. 8, 369-375.

Mrak, R. E., Sheng, J. G., and Griffin, W. S. (1996). Correlation of astrocytic S100 beta expression with dystrophic neurites in amyloid plaques of Alzheimer's disease. J. Neuropathol. Exp. Neurol. 55, 273-279. doi: 10.1097/00005072199603000-00002

Murrell, J., Farlow, M., Ghetti, B., and Benson, M. D. (1991). A mutation in the amyloid precursor protein associated with hereditary Alzheimer's disease. Science 254, 97-99. doi: 10.1126/science. 1925564

Okun, E., Mattson, M. P., and Arumugam, T. V. (2010). Involvement of $\mathrm{Fc}$ receptors in disorders of the central nervous system. Neuromol. Med. 12, 164-178. doi: 10.1007/s12017-009-8099-5

Orgogozo, J.-M., Gilman, S., Dartigues, J.-F., Laurent, B., Puel, M., Kirby, L., et al. (2003). Subacute meningoencephalitis in a subset of patients with $\mathrm{AD}$ after $\mathrm{A} \beta 42$ immunization. Neurology 61, 46-54. doi: 10.1212/ 01.WNL.0000073623.84147.A8

Patel, N. S., Paris, D., Mathura, V., Quadros, A. N., Crawford, F. C., and Mullan, M. J. (2005). Inflammatory cytokine levels correlate with amyloid load in transgenic mouse models of Alzheimer's disease. J. Neuroinflammation 2, 9. doi: 10.1186/1742-2094-2-9

Pekkarinen, P. T., Vaali, K., Junnikkala, S., Rossi, L. H., Tuovinen, H., Meri, S., et al. (2011). A functional complement system is required for normal $\mathrm{T}$ helper cell differentiation. Immunobiology 216, 737-743. doi: 10.1016/j.imbio.2010.10.004

Quintanilla, R. A., Orellana, D. I., Gonzalez-Billault, C., and Maccioni, R. B. (2004). Interleukin-6 induces Alzheimer-type phosphorylation of tau protein by deregulating the cdk5/p35 pathway. Exp. Cell Res. 295, 245-257. doi: 10.1016/j.yexcr.2004.01.002

Ransohoff, R. M., Glabinski, A., and Tani, M. (1996). Chemokines in immune-mediated inflammation of the central nervous system. Cytokine Growth Factor Rev. 7, 35-46. doi: 10.1016/1359-6101(96)00003-2

Rezai-Zadeh, K., Gate, D., and Town, T. (2009). CNS infiltration of peripheral immune cells: D-Day for neurodegenerative disease? J. Neuroimmune Pharmacol. 4, 462-475. doi: 10.1007/s11481-009-9166-2

Ricklin, D., Hajishengallis, G., Yang, K., and Lambris, J. D. (2010). Complement: a key system for immune surveillance and homeostasis. Nat. Immunol. 11, 785-797. doi: 10.1038/ni.1923

Ridnour, L. A., Barasch, K. M., Windhausen, A. N., Dorsey, T. H., Lizardo, M. M., Yfantis, $H$. G., et al. (2012). Nitric oxide synthase and breast cancer: role of TIMP-1 in NO-mediated Akt activation. PLOS ONE 7:e44081. doi: 10.1371/journal.pone.0044081

Ringman, J. M., O’Neill, J., Geschwind, D., Medina, L., Apostolova, L. G., Rodriguez, Y., et al. (2007). Diffusion tensor imaging in preclinical and presymptomatic carriers of familial Alzheimer's disease mutations. Brain 130, 1767-1776. doi: 10.1093/brain/awm102

Ringheim, G. E., Szczepanik, A. M. Petko, W., Burgher, K. L., Zhu, S. Z., and Chao, C. C. (1998). Enhancement of beta-amyloid precursor protein transcription and expression by the soluble interleukin-6 receptor/interleukin6 complex. Brain Res. Mol.
Brain Res. 55, 35-44. doi: 10.1016/S0169-328X(97)00356-2

Rogers, J., Cooper, N. R., Webster, S., Schultz, J., McGeer, P. L., Styren, S. D., et al. (1992). Complement activation by beta-amyloid in Alzheimer disease. Proc. Natl. Acad. Sci. U.S.A. 89, 10016-10020. doi: 10.1073/pnas.89.21.10016

Rossi, F., and Bianchini, E. (1996). Synergistic induction of nitric oxide by beta-amyloid and cytokines in astrocytes. Biochem. Biophys. Res. Commun. 225, 474-478. doi 10.1006/bbrc.1996.1197

Roth, A. D., Ramirez, G., Alarcon, R., and Von Bernhardi, R. (2005). Oligodendrocytes damage in Alzheimer's disease: beta amyloid toxicity and inflammation. Biol. Res. 38, 381-387. doi: 10.4067/S071697602005000400011

Rozemuller, J. M., Eikelenboom, P., and Stam, F. C. (1986). Role of microglia in plaque formation in senile dementia of the Alzheimer type. An immunohistochemical study. Virchows Arch. B Cell Pathol. Incl. Mol. Pathol. 51, 247-254. doi: 10.1007/BF02899034

Rozkalne, A., Spires-Jones, T. L., Stern, E. A., and Hyman, B. T. (2009). A single dose of passive immunotherapy has extended benefits on synapses and neurites in an Alzheimer's disease mouse model. Brain Res. 1280, 178-185. doi: 10.1016/j.brainres.2009.05.045

Rubartelli, A., and Lotze, M. T. (2007). Inside, outside, upside down: damage-associated molecularpattern molecules (DAMPs) and redox. Trends Immunol. 28 429-436. doi: 10.1016/j.it.2007. 08.004

Saez, T. E., Pehar, M., Vargas, M. Barbeito, L., and Maccioni, R. B. (2004). Astrocytic nitric oxide triggers tau hyperphosphorylation in hippocampal neurons. In Vivo 18, 275-280.

Salloway, S., Sperling, R., Gilman, S., Fox, N., Blennow, K., Raskind, M., et al. (2009). A phase 2 multiple ascending dose trial of bapineuzumab in mild to moderate Alzheimer disease. Neurology 73, 2061-2070. doi: 10.1212/WNL.0b013e3181c67808

Sastre, M., Dewachter, I., Rossner, S., Bogdanovic, N., Rosen, E. Borghgraef, P., et al. (2006). Nonsteroidal anti-inflammatory drugs repress -secretase gene promoter activity by the activation of PPAR. Proc. Natl. Acad. Sci. U.S.A. 103, 443-448.

Sheng, J. G., Zhu, S. G., Jones, R. A., Griffin, W. S., and Mrak, R. E.
(2000). Interleukin-1 promotes expression and phosphorylation of neurofilament and tau proteins in vivo. Exp. Neurol. 163, 388-391. doi: 10.1006/exnr.2000.7393

Sisodia, S. S., Kim, S. H., and Thinakaran, G. (1999). Function and dysfunction of the presenilins. Am. J. Hum. Genet. 65, 7-12. doi: $10.1086 / 302475$

Smyth, M. D., Cribbs, D. H., Tenner, A. J., Shankle, W. R., Dick, M., Kesslak, J. P., et al. (1994). Decreased levels of $\mathrm{Clq}$ in cerebrospinal fluid of living Alzheimer patients correlate with disease state. Neurobiol. Aging 15, 609-614. doi: 10.1016/01974580(94)00055-7

Sofroniew, M. V., and Vinters, H. V. (2010). Astrocytes: biology and pathology. Acta Neuropathol. 119, 7-35. doi: 10.1007/s00401-0090619-8

Spires-Jones, T. L., Mielke, M. L., Rozkalne, A., Meyer-Luehmann, M., De Calignon, A., Bacskai, B. J., et al. (2009). Passive immunotherapy rapidly increases structural plasticity in a mouse model of Alzheimer disease. Neurobiol. Dis. 33, 213-220. doi: 10.1016/j.nbd. 2008.10.011

Sterka, D. Jr., and Marriott, I. (2006). Characterization of nucleotidebinding oligomerization domain (NOD) protein expression in primary murine microglia. J. Neuroimmunol. 179, 65-75. doi: 10.1016/j.jneuroim.2006.06.009

Sung, S., Yang, H., Uryu, K., Lee, E. B., Zhao, L., Shineman, D., et al. (2004). Modulation of nuclear factor-кb activity by indomethacin influences $a \beta$ levels but not a $\beta$ precursor protein metabolism in a model of alzheimer's disease. Am. J. Pathol. 165, 2197-2206. doi: 10.1016/ S0002-9440(10)63269-5

Swaab, D. F., Raadsheer, F. C., Endert, E., Hofman, M. A., Kamphorst, W., and Ravid, R. (1994). Increased cortisol levels in aging and Alzheimer's disease in postmortem cerebrospinal fluid. J. Neuroendocrinol. 6, 681-687. doi: 10.1111/j.13652826.1994.tb00635.x

Szekely, C. A., Green, R. C., Breitner, J. C. S., Ostbye, T., Beiser, A S., Corrada, M. M., et al. (2008). No advantage of "A $\beta 42$-lowering" NSAIDs for prevention of AD insix pooled cohort studies. Neurology 70, 2291-2298. doi: 10.1212/01.wnl. 0000313933.17796.f6

Takeuchi, H., Jin, S., Wang, J., Zhang, G., Kawanokuchi, J., Kuno, R., et al. (2006). Tumor necrosis factor-alpha induces neurotoxicity via glutamate 
release from hemichannels of activated microglia in an autocrine manner. J. Biol. Chem. 281, 21362-21368. doi: 10.1074/jbc. M600504200

Tan, J., Town, T., Paris, D., Mori, T., Suo, Z., Crawford, F., et al. (1999). Microglial activation resulting from CD40-CD40L interaction after beta-amyloid stimulation. Science 286, 2352-2355. doi: $10.1126 /$ science.286.5448.2352

Tarkowski, E., Issa, R., Sjogren, M., Wallin, A., Blennow, K., Tarkowski, A., et al. (2002). Increased intrathecal levels of the angiogenic factors VEGF and TGF-beta in Alzheimer's disease and vascular dementia. Neurobiol. Aging 23, 237-243. doi: 10.1016/ S0197-4580(01)00285-8

Tesseur, I., Zou, K., Esposito, L., Bard, F., Berber, E., Can, J. V., et al. (2006). Deficiency in neuronal TGF-beta signaling promotes neurodegeneration and Alzheimer's pathology. J. Clin. Invest. 116, 3060-3069. doi: 10.1172/JCI27341

Thal, L. J., Ferris, S. H., Kirby, L., Block, G. A., Lines, C. R., Yuen, E., et al. (2005). A randomized, double-blind, study of rofecoxib in patients with mild cognitive impairment. Neuropsychopharmacology 30, 1204-1215. doi: 10.1038/sj.npp. 1300690

Torreilles, F., Salman-Tabcheh, S., Guerin, M., and Torreilles, J. (1999). Neurodegenerative disorders: the role of peroxynitrite. Brain Res. Brain Res. Rev. 30, 153-163. doi: 10.1016/S0165-0173(99)00014-4

Town, T., Nikolic, V., and Tan, J. (2005). The microglial "activation" continuum: from innate to adaptive responses. J. Neuroinflammation 2, 24. doi: 10.1186/1742-2094-2-24

Van Dam, D., Coen, K., and De Deyn, P. P. (2010). Ibuprofen modifies cognitive disease progression in an Alzheimer's mouse model. J. Psychopharmacol. 24, 383-388. doi: 10.1177/0269881108097630

Vane, J., and Botting, R. (1987). Inflammation and the mechanism of action of anti-inflammmatory drugs. FASEB J. 1, 89-96.

Vellas, B., Black, R., Thal, L. J., Fox, N. C., Daniels, M., McLennan, G., et al. (2009). Long-term follow-up of patients immunized with AN1792: reduced functional decline in antibody responders. Curr. Alzheimer Res. 6, 144. doi: 10.2174/156720509787602852

Wajant, H., Pfizenmaier, K., and Scheurich, P. (2003). Tumor necrosis factor signaling. Cell Death Differ. 10, 45-65. doi: 10.1038/sj.cdd.4401189
Walker, D. G., Kim, S. U., and McGeer, P. L. (1995). Complement and cytokine gene expression in cultured microglial derived from postmortem human brains. J. Neurosci. Res. 40, 478-493. doi: 10.1002/jnr.490400407

Walker, D. G., and Lue, L. F. (2005). Investigations with cultured human microglia on pathogenic mechanisms of Alzheimer's disease and other neurodegenerative diseases. J. Neurosci. Res. 81, 412-425. doi: 10.1002/jnr.20484

Wallace, M. N., Geddes, J. G., Farquhar, D. A., and Masson, M. R. (1997). Nitric oxide synthase in reactive astrocytes adjacent to beta-amyloid plaques. Exp. Neurol. 144, 266-272. doi: 10.1006/exnr.1996.6373

Webster, S. D., Yang, A. J., Margol, L., Garzon-Rodriguez, W. Glabe, C. G., and Tenner, A. J. (2000). Complement component Clq modulates the phagocytosis of Abeta by microglia. Exp. Neurol. 161, 127-138. doi: 10.1006/exnr.1999.7260

Wells, T. N., Power, C. A., and Proudfoot, A. E. (1998). Definition, function and pathophysiological significance of chemokine receptors. Trends Pharmacol. Sci. 19, 376-380. doi: 10.1016/ S0165-6147(98)01247-4

Westin, K., Buchhave, P., Nielsen, H., Minthon, L., Janciauskiene, S., and Hansson, O. (2012). CCL2 is associated with a faster rate of cognitive decline during early stages of Alzheimer's disease. PLoS ONE 7:e30525. doi: 10.1371/journal.pone. 0030525

Wiessner, C., Wiederhold, K. H., Tissot, A. C., Frey, P., Danner, S., Jacobson, L. H., et al. (2011). The second-generation active Abeta immunotherapy CAD106 reduces amyloid accumulation in APP transgenic mice while minimizing potential side effects. J. Neurosci. 31, 9323-9331. doi: 10.1523/ JNEUROSCI.0293-11.2011

Williams, T. J. (1978). The role of prostaglandins in inflammation. Ann. R. Coll. Surg. Engl. 60, 198-201.

Wisniewski, H. M., Barcikowska, M. and Kida, E. (1991). Phagocytosis of beta/A4 amyloid fibrils of the neuritic neocortical plaques. Acta Neuropathol. 81, 588-590. doi: 10.1007/BF00310142

Wyss-Coray, T., Lin, C., Yan, F., Yu, G. Q., Rohde, M., McConlogue, L., et al. (2001). TGF-betal promotes microglial amyloid-beta clearance and reduces plaque burden in transgenic mice. Nat. Med. 7, 612-618. doi: 10.1038/87945
Wyss-Coray, T., Loike, J. D., Brionne, T. C., Lu, E., Anankov, R., Yan, F., et al. (2003). Adult mouse astrocytes degrade amyloid-beta in vitro and in situ. Nat. Med. 9, 453-457. doi: $10.1038 / \mathrm{nm} 838$

Wyss-Coray, T., Masliah, E., Mallory, M., McConlogue, L., JohnsonWood, K., Lin, C., et al. (1997). Amyloidogenic role of cytokine TGF-betal in transgenic mice and in Alzheimer's disease. Nature 389, 603-606. doi: 10.1038/39321

Wyss-Coray, T., Yan, F., Lin, A. H., Lambris, J. D., Alexander, J. J., Quigg, R. J., et al. (2002). Prominent neurodegeneration and increased plaque formation in complement-inhibited Alzheimer's mice. Proc. Natl. Acad. Sci. U.S.A. 99, 10837-10842. doi: 10.1073/pnas.162350199

Xia, M. Q., Qin, S. X., Wu, L. J., Mackay, C. R., and Hyman, B. T. (1998) Immunohistochemical study of the beta-chemokine receptors CCR3 and CCR5 and their ligands in normal and Alzheimer's disease brains. Am. J. Pathol. 153, 31-37. doi: 10.1016/S0002-9440(10)65542-3

Xiang, Z., Ho, L., Valdellon, J., Borchelt, D., Kelley, K., Spielman, L., et al. (2002a). Cyclooxygenase (COX)-2 and cell cycle activity in a transgenic mouse model of Alzheimer's disease neuropathology. Neurobiol. Aging 23, 327-334. doi: 10.1016/S01974580(01)00282-2

Xiang, Z., Ho, L., Yemul, S., Zhao, Z., Qing, W., Pompl, P., et al. (2002b). Cyclooxygenase-2 promotes amyloid plaque deposition in a mouse model of Alzheimer's disease neuropathology. Gene Expr. 10, 271-278.

Yamagata, K., Andreasson, K. I., Kaufmann, W. E., Barnes, C. A., and Worley, P. F. (1993). Expression of a mitogen-inducible cyclooxygenase in brain neurons: regulation by synaptic activity and glucocorticoids. Neuron 11, 371-386. doi 10.1016/0896-6273(93)90192-T

Yamamoto, M., Horiba, M., Buescher, J. L., Huang, D., Gendelman, H. E., Ransohoff, R. M., et al. (2005). Overexpression of monocyte chemotactic protein-1/CCL2 in beta-amyloid precursor protein transgenic mice show accelerated diffuse beta-amyloid deposition. Am. J. Pathol. 166, 1475-1485. doi: 10.1016/S00029440(10)62364-4

Yamamoto, M., Kiyota, T., Horiba, M., Buescher, J. L., Walsh, S. M., Gendelman, H. E., et al. (2007). Interferon-gamma and tumor necrosis factor-alpha regulate amyloid-beta plaque deposition and beta-secretase expression in Swedish mutant APP transgenic mice. Am. J. Pathol. 170, 680-692. doi: 10.2353/ajpath.2007.060378

Yao, Y.-Y., Liu, D.-M., Xu, D.-F., and Li, W.-P. (2007). Memory and learning impairment induced by dexamethasone in senescent but not young mice. Eur. J. Pharmacol. 574, 20-28. doi: 10.1016/j.ejphar.2007. 07.021

Yermakova, A. V., Rollins, J., Callahan, L. M., Rogers, J., and O'Banion, M. K. (1999). Cyclooxygenase-1 in human Alzheimer and control brain: quantitative analysis of expression by microglia and CA3 hippocampal neurons. J. Neuropathol. Exp. Neurol. 58, 1135-1146. doi: 10.1097/00005072199911000-00003

Yip, A. G., Green, R. C., Huyck, M., Cupples, L. A., and Farrer, L. A. (2005). Nonsteroidal antiinflammatory drug use and Alzheimer's disease risk: the MIRAGE Study. BMC Geriatr. 5:2. doi: 10.1186/1471-2318-5-2

Zilka, N., Kazmerova, Z., Jadhav, S., Neradil, P., Madari, A., Obetkova, D., et al. (2012). Who fans the flames of Alzheimer's disease brains? Misfolded tau on the crossroad of neurodegenerative and inflammatory pathways. J. Neuroinflammation 9, 47. doi: 10.1186/1742-2094-9-47

Conflict of Interest Statement: The authors declare that the research was conducted in the absence of any commercial or financial relationships that could be construed as a potential conflict of interest.

Received: 04 May 2013; paper pending published: 09 June 2013; accepted: 25 July 2013; published online: 13 August 2013.

Citation: Meraz-Ríos MA, Toral-Rios $D$, Franco-Bocanegra D, VilledaHernández J and Campos-Peña V (2013) Inflammatory process in Alzheimer's Disease. Front. Integr. Neurosci. 7:59. doi: 10.3389/fnint.2013.00059 Copyright (c) 2013 Meraz-Ríos, Toral-Rios, Franco-Bocanegra, VilledaHernández and Campos-Peña. This is an open-access article distributed under the terms of the Creative Commons Attribution License (CC BY). The use, distribution or reproduction in other forums is permitted, provided the original author(s) or licensor are credited and that the original publication in this journal is cited, in accordance with accepted academic practice. No use, distribution or reproduction is permitted which does not comply with these terms. 